Document downloaded from:

http://hdl.handle.net/10251/80025

This paper must be cited as:

Benjamin W Knox; Genzale, C.; LYLE M. PICKETT; José M García-Oliver; Vera-TudelaFajardo, WM. (2015). Combustion Recession after End of Injection in Diesel Spray. SAE International Journal of Fuel and Lubricants. 8(2):1-17. doi:10.4271/2015-01-0797.

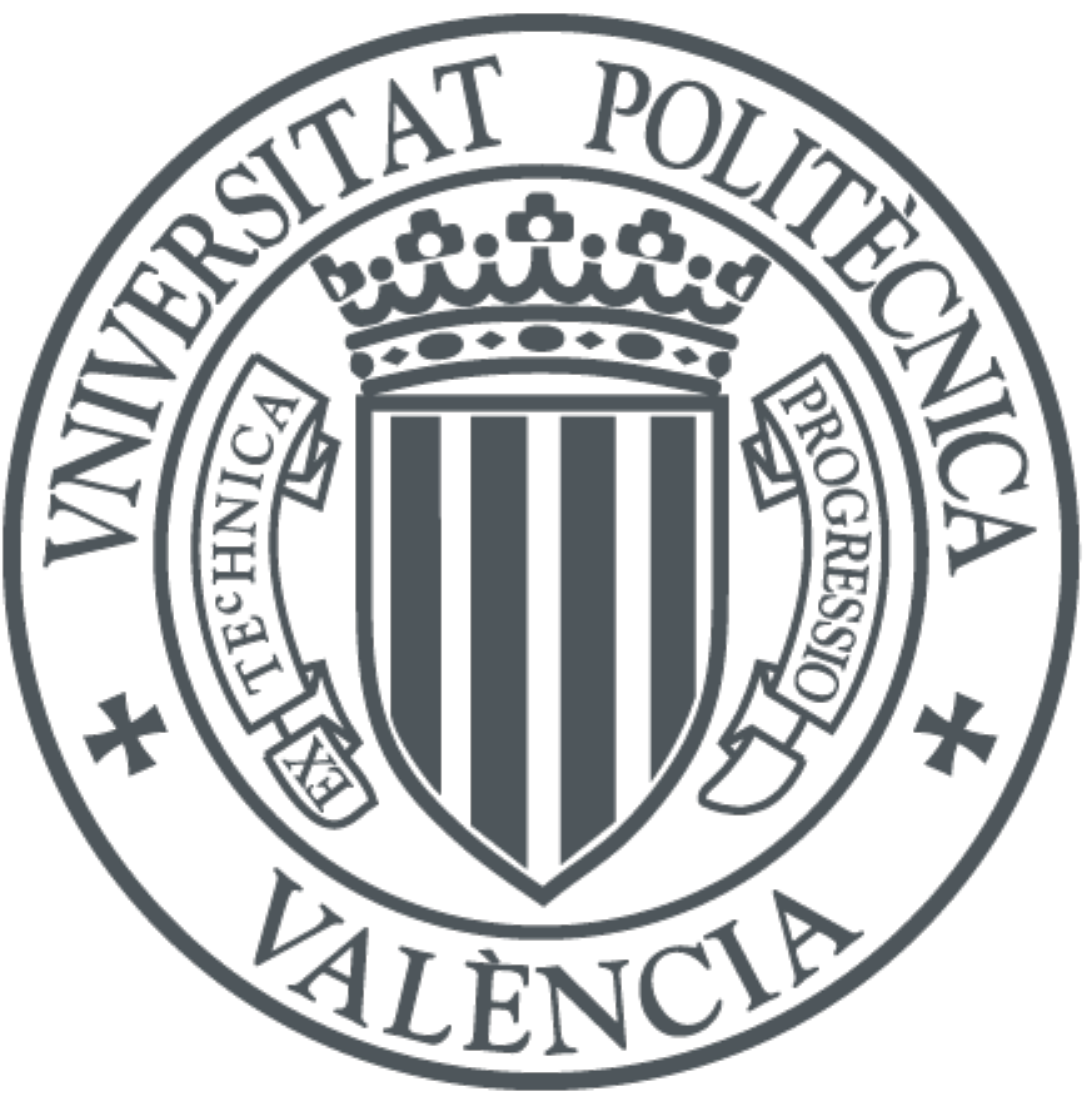

The final publication is available at

http://dx.doi.org/10.4271/2015-01-0797

Copyright SAE International

Additional Information 


\title{
Combustion Recession after End of Injection in Diesel Sprays
}

\author{
Author, co-author (Do NOT enter this information. It will be pulled from participant tab in \\ MyTechZone) \\ Affiliation (Do NOT enter this information. It will be pulled from participant tab in MyTechZone)
}

\begin{abstract}
This work contributes to the understanding of physical mechanisms that control flashback, or more appropriately combustion recession, in diesel-like sprays. Combustion recession is the process whereby a lifted flame retreats back towards the injector after end-of-injection under conditions that favor autoignition. The motivation for this study is that failure of combustion recession can result in unburned hydrocarbon emissions.
\end{abstract}

A large dataset, comprising many fuels, injection pressures, ambient temperatures, ambient oxygen concentrations, ambient densities, and nozzle diameters is used to explore experimental trends for the behavior of combustion recession. Then, a reduced-order model, capable of modeling non-reacting and reacting conditions, is used to help interpret the experimental trends. Finally, the reduced-order model is used to predict how a controlled ramp-down rate-ofinjection can enhance the likelihood of combustion recession for conditions that would not normally exhibit combustion recession.

In general, fuel, ambient conditions, and the spray rate-of-injection transient during the end-of-injection determine the success or failure of combustion recession. The likelihood of combustion recession increases for higher ambient temperatures and oxygen concentrations as well as for higher reactivity fuels. In the transition between high and low ambient temperature (or oxygen concentration), the behavior of combustion recession changes from spatially sequential ignition to separated, or isolated, ignition sites that eventually merge. In contradistinction to typical diesel ignition delay trends where the autoignition times are longer for increasing injection pressure, the time required for combustion recession increases with injection pressure.

\section{Introduction}

Unburned hydrocarbon (UHC) emissions under low-temperature combustion (LTC) operating conditions have recently been linked to the end-of-injection transient in diesel injectors and the impact of this transient on the combustion of near-nozzle mixtures [1,2]. Because LTC conditions are typically highly dilute, with ambient oxygen concentrations near $15 \%$, the lifted flame, or high-temperature reaction zone, occurs relatively far downstream due to the increased mixing required to reach ignitable fuel-ambient mixtures. After the end of injection, the position of the lifted flame, or high-temperature reaction zone, is observed to remain far downstream of the injector, leaving a large region of unburned or partially burned fuel-air mixture upstream [1]. Shown in Figure 1 is a schematic of this process though the scenario depicted is one where the lifted-flame propagates upstream. Failure of the lifted flame to retreat back towards the injector after end-of-injection, and thus consume the unburned fuel-air mixture, has been suggested to be the consequence of locally enhanced entrainment (indicated by the larger arrows during end-of-injection in Figure 1), termed an "entrainment wave", following the end-of-injection transient [1]. The entrainment wave has been linked to the lack of combustion in near-nozzle mixtures because it rapidly leans mixtures upstream of the lifted flame such that these regions are incapable of supporting second-stage ignition. Furthermore, since the mass of fuel in the jet increases as the square of the distance from the injector under steady injection, the potential for UHC emitted increases as the square of the flame lift-off length (LOL). Thus, since LOL are relatively long for low-temperature combustion operating conditions, the lack of flame retreat after endof-injection is a major concern.

Under high-temperature conventional diesel combustion operating conditions, however, there is evidence to suggest that the lifted flame does propagate back towards the injector after the end of injection [3, $4,5]$. Multiple participants of the Engine Combustion Network (ECN) have observed this process, including Sandia National Laboratories and Eindhoven University of Technology, though no published works have focused on it [6]. Other researchers who have observed such phenomena have referred to this as "flashback" [1, 4]. This term has likely been used due to its commonality with similar lifted-flame phenomenon observed in gas-turbine studies. However, under typical diesel engine operating conditions, autoignition rather than flame propagation may play a dominating role such that combustion recession is a more appropriate term compared to flashback [3]. A schematic of the combustion recession process is shown in Figure 1. 

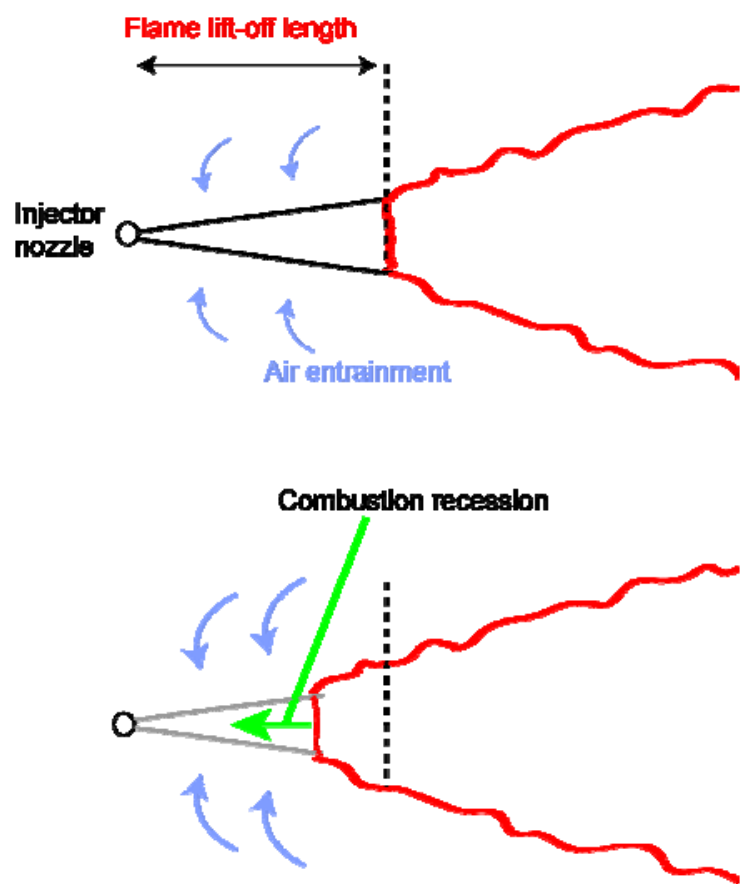

Figure 1 - Schematic of combustion recession

As previously discussed, the advent of low-temperature combustion and the associated effects of end-of-injection over-leaning and UHC emission have been primarily responsible for motivating an interest in end-of-injection combustion recession. In fact, combustion recession can even be observed in the early optical engine studies of Espey and Dec [7], but it has been given little attention to date. This is likely due to the fact that their experiments were under conventional, or high-temperature, combustion conditions which are more likely to exhibit combustion recession. Moreover, even if combustion recession were not observed, the potential for UHC is low because high-temperature combustion lift-off lengths are short. Now though, with optical engine studies are aimed directly at examining the fate of upstream near-nozzle mixtures and their impact on UHC $[1,2]$., Ttheir findings suggest a dominating trend towards a lack of combustion recession under low-temperature combustion conditions warrantings an interest in understanding the nature of these end-of-injection combustion transients and the conditions which support or suppress combustion recession.

Though there have been no known targeted studies on the conditions that either support or suppress combustion recession, prior research on end-of-injection soot behavior provides further evidence for a transition to no combustion recession for highly dilute or LTC conditions. Indeed, researchers have observed the behavior of soot recession back towards the injector nozzle for transition from high to low-temperature combustion operating conditions $[4,5]$. Bobba, Genzale, and Musculus measured the spatial and temporal development of soot luminosity and observed that as the top-deadcenter motored temperature decreased from $1000 \mathrm{~K}$ to $875 \mathrm{~K}$, meaning a change from high to low-temperature combustion conditions, the soot luminosity stopped retreating back toward the injector after end-of-injection [4]. While not specifically addressed, soot imaging by Singh, Reitz, and Musculus also show a similar change in the behavior of soot recession between high and lowtemperature combustion operating regimes [5]. While the observation of soot recession from these natural luminosity measurements is an indicator that combustion recession has also occurred,

Page 2 of 18 chemiluminescence from ignition radicals is much weaker than soot luminosity and would not likely be captured by these measurements. Thus, the ambient conditions where a transition from combustion recession to no combustion recession occurs cannot be readily identified from these measurements. High-sensitivity chemiluminescence imaging, like that used in [1], or an indirect measurement of mixture temperatures from schlieren [8], is needed to resolve the relatively weak emission from combustion radicals without interference from soot.

Other work focused on the impact of end-of-injection transients on near-nozzle fuel-ambient mixing and liquid vaporization suggests that, in addition to ambient conditions, the characteristics of the endof-injection mass flow rate will influence the likelihood of combustion recession. Kook, Pickett, and Musculus have demonstrated that the liquid penetration length also undergoes a recession back towards the injector from its quasi-steady value during end of injection [9]. Using a 1-D mixing model, they showed that the details of the entrainment wave dictate the behavior of liquid length recession. Specifically, they show that the speed and magnitude of the entrainment wave determine the liquid penetration distance and the liquid recession rate. Both the speed and magnitude of the entrainment wave are a function of the end-of-injection transient, which depends on the injection velocity, nozzle orifice area in addition the ramp down duration. Higher injection pressures and larger nozzle orifice diameters were both shown to decrease the liquid penetration distance and increase the liquid recession rate. However, the ramp down duration was demonstrated to increase the liquid penetration distance and decrease the liquid recession rate. Extrapolating from their results, it is expected that the combustion recession behavior is also controlled by the end-of-injection transient of the jet because ignition reactions are sensitive to the relative amounts of fuel and ambient gases.

The objective of this work is to identify ambient and injection conditions that support and/or suppress combustion recession in order to develop fundamental insight on the nature of combustion recession. Diagnostics are employed that are sensitive to reactive species, without interference of soot, including high-speed chemiluminescence and schlieren imaging during the end-of-injection transient. A large dataset is used, primarily centered on a sweep of ambient and injection conditions surrounding the ECN Spray A condition [6], to develop trends of the existence of combustion recession as well as the time required for combustion recession at each condition. Since the dataset can be sparse for certain conditions, identification of areas that need further attention is another major goal of this work.

\section{Experiments}

Experiments were performed at two institutions, namely Sandia National Laboratories (Sandia) and CMT - Motores Térmicos (CMT). Below, we summarize the experimental facilities and diagnostics employed at each institution to measure combustion recession. The fuel injection and ambient operating conditions studied are also summarized.

\section{Spray Combustion Vessels}

Data was obtained in two optically-accessible combustion vessels; one that is a pre-burn, constant volume type vessel used at Sandia [10] and the other is a flow-through constant pressure type vessel employed at CMT [11]. Both are capable of simulating the ambient 
conditions inside of a diesel engine. Table 1 contains several columns where the subscript of each denotes in which facility the measurements were completed. A subscript of 1 denotes the pre-burn constant volume type and a subscript of 2 denotes the flow-through constant pressure type vessel. A detailed comparison of these vessels, including diagnostics used in this paper is given in Refs. [12] and [13].

\section{Fuel Injectors}

A common rail fuel injector, the so-called Spray A injector, was used for the majority of the experiments performed at Sandia and CMT. This injector is a standard within the ECN group, an international collaboration among different research laboratories in the world [10]. The injector has a single-orifice nozzle with a nominal diameter of 90 $\mu \mathrm{m}$. The experiments performed at CMT were conducted with a specific injector, namely model \#675. Additional single-orifice, minisac-type injector tips similar to Spray A were also used for experiments at Sandia. The orifice diameter for each injector tip is shown in Table 1. Detailed information about the nozzle shapes are available at [6].

The measured end of injection transient for Spray A is shown in Figure 2 where time is given relative to the start of ramp down [6]. Throughout this work, time will be given after start of ramp down (aSORD) because after this instance changes in the mixing due to the end of injection will then have an effect of combustion. The ramp down process lasts approximately $100 \mu$ s and is reasonably linear during this period. Note that time zero is positioned at the instance when the rate-of-injection drops below its steady-state value, reflecting the start of the end-of-injection transient. As shown in Figure 2, due to acoustic pressure oscillations in the fuel system, fluctuations in the steady-state injection rate are observed. Thus, the steady-state injection rate is quantified by taking an average of the measured rate-of-injection from -4000 (not shown) to -100 $\mu$ s aSOR D. The positive values of the injection rate seen between $100 \mu$ s and $300 \mu$ s are most likely an artifact of the rate-of-injection measurement device. As shown and discussed later in Figure 4, we don't see evidence of liquid fuel at these times in our high-speed images. Therefore, we have considered injection to completely end when the rate of injection signal crosses zero at $100 \mu \mathrm{s}$.

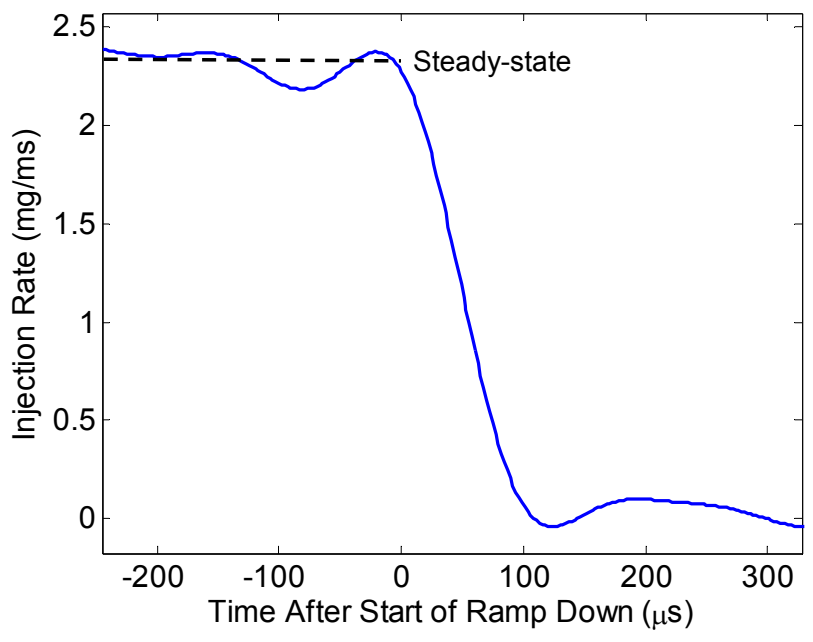

Figure 2 - Measured rate of injection for Spray A [6]

\section{Fuels}

Several single-component, binary-blend, and multi-component fuels were used in this work. The binary blend was a gasoline-type primary reference fuel (PRF) consisting of $n$-heptane and iso-octane where the percentage of iso-octane is denoted, e.g. PRF20 [14]. The gasoline was locally available and details of the diesel fuel are available at [6].

\section{Test Conditions}

A large range of test conditions have been explored for the experimental data used in this study. The goal of such a large test matrix is to observe trends in the behavior of combustion recession as conditions are transitioned from low to high-temperature combustion operating conditions. As previously stated, the data is a combination from two sources, Sandia and CMT.

Table 1 - Test conditions for combustion recession data. Each column has a subscript to denote in which facility the measurements were completed. A subscript of 1 denotes the pre-burn constant volume type [10] and a subscript of 2 denotes the flow-through constant pressure type vessel [11].

\begin{tabular}{|l|l|l|l|l|l|}
\hline & N-heptane $_{1,2}$ & Diesel $_{1}$ & Gasoline $_{1}$ & Dodecane $_{1,2}$ & PRF20 $_{2}$ \\
\hline $\begin{array}{l}\text { Nozzle } \\
\text { diameter } \\
(\mu \mathrm{m})\end{array}$ & 100,90 & $\begin{array}{l}90, \\
110, \\
180\end{array}$ & 180 & 90 & 90 \\
\hline $\begin{array}{l}\text { Ambient } \\
\text { temperature } \\
(\mathrm{K})\end{array}$ & $850-1000$ & $\begin{array}{l}800- \\
1200\end{array}$ & $\begin{array}{l}900- \\
1300\end{array}$ & $750-1200$ & $800-950$ \\
\hline $\begin{array}{l}\text { Ambient } \\
\text { density } \\
\left(\mathrm{kg} / \mathrm{m}^{3}\right)\end{array}$ & $14.8,22.8$ & $\begin{array}{l}14.8, \\
22.8\end{array}$ & 14.8 & $7.6-22.8$ & 22.8 \\
\hline $\begin{array}{l}\text { Ambient } \mathrm{O}_{2} \\
(\%)\end{array}$ & $15-21$ & $15-21$ & 21 & $13-21$ & $15-21$ \\
\hline $\begin{array}{l}\text { Injection } \\
\text { pressure } \\
(\text { MPabar })\end{array}$ & 1500 & $900-$ & 900 & $300-1500$ & $500-$ \\
\hline
\end{tabular}

Two conditions of relevance to the diesel engine community that have been agreed upon by the ECN are termed Spray A and Spray H. Table 1 encompasses both conditions as well as parameter variations on each. Important characteristics of Spray A include the use of ndodecane as fuel, $90 \mu \mathrm{m}$ single, on-axis orifice, $150 \mathrm{MPa}$ injection pressure, $22.8 \mathrm{~kg} / \mathrm{m}^{3}$ ambient density, $900 \mathrm{~K}$ ambient temperature, and $15 \% \mathrm{O}_{2}$ ambient oxygen concentration. Defining aspects of Spray $\mathrm{H}$ include the use of $\mathrm{n}$-heptane as fuel, $100 \mu \mathrm{m}$ single, on-axis orifice, $150 \mathrm{MPa}$ injection pressure, $14.8 \mathrm{~kg} / \mathrm{m}^{3}$ ambient density, $1000 \mathrm{~K}$ ambient temperature. More details on each condition can be found at Ref. 6.

\section{Diagnostics}

Two optical techniques are used to detect and identify combustion recession. A key feature of these techniques is that they are highspeed such that the combustion recession process can be resolved in time.

The broadband chemiluminescence imaging setup was used to detect a large range of electronically-excited species that appear at the onset 
of high-temperature combustion $[15,16,17]$. To focus on the recession of ignition rather than soot, rejection of soot luminosity was achieved with a $600-\mathrm{nm}$ short-pass filter using the setup provided in Bardi et al. [13]. This filter allowed for the collection of electronically-excited radicals, e.g. $\mathrm{CH}^{*}$ and $\mathrm{C} 2 *$, while eliminating a portion of the emission and background flare due to soot incandescence in the lift-off region. As detailed in Ref. [13], visiblewavelength emission can be reliably utilized to identify hightemperature ignition timing because soot luminosity occurs after autoignition. When overall soot luminosity is low and it occurs downstream of the lift-off length, chemiluminescence at the lift-off length may also be measured after ignition, as demonstrated in Ref. [18]. In addition, dynamic background corrections were implemented in this study to distinguish combustion chemiluminescence from the soot luminosity flare reflected outside of the spray, as detailed in [19].

Schlieren imaging was used to identify regions of high-temperature products near the injector after the end of injection that are the result of combustion recession. Schlieren is a line-of-sight technique that is sensitive to index of refractive gradients anywhere along the beam path. Unfortunately, thermal gradients at the windows of the combustion vessel are also visible that create a slowly-evolving and noisy background. The Sandia schlieren setup is more sensitive to schlieren disturbances, with more details given in Ref [13]. Consequently, smaller temperature non-uniformities at the wall appear as a distinct background. Comparatively, the CMT schlieren setup is less affected by background inhomogeneities. Nevertheless, high-temperature combustion gradients of the spray are easily measured. Further details regarding the CMT schlieren setup are found in Ref. [14, 21]. Recent changes to the Sandia schlieren setup have increased the light source aperture from $1 \mathrm{~mm}$ to $3 \mathrm{~mm}$ to reduce the effect of background inhomogeneities [3].

Table 2- Specifications of the optical diagnostics employed

\begin{tabular}{|l|l|l|l|}
\hline & $\begin{array}{l}\text { Broadband } \\
\text { chemiluminescence }\end{array}$ & Sandia schlieren & CMT schlieren \\
\hline Camera & $\begin{array}{l}\text { Phantom v7.1 } \\
\text { CMOS }\end{array}$ & $\begin{array}{l}\text { Phantom v7.1 } \\
\text { CMOS }\end{array}$ & $\begin{array}{l}\text { Photron SA-5 } \\
\text { CMOS }\end{array}$ \\
\hline Lens & $\begin{array}{l}\text { Nikon } 50 \mathrm{~mm} \\
(\mathrm{f} / 1.2)\end{array}$ & $\begin{array}{l}\text { Nikon } 85 \mathrm{~mm} \\
(\mathrm{f} / 2.8)\end{array}$ & $\begin{array}{l}\text { Nikon } 50 \mathrm{~mm} \\
(\mathrm{f} / 1.8)\end{array}$ \\
\hline Filter & $600 \mathrm{~nm}$ short-pass & $450 \mathrm{~nm}$ band-pass & $\begin{array}{l}360-580 \mathrm{~nm} \text { band } \\
\text { pass }\end{array}$ \\
\hline Exposure & $46 \mu \mathrm{s}$ & $10 \mu \mathrm{s}$ & $4 \mu \mathrm{s}$ \\
\hline Framing Period & $50 \mu \mathrm{s}$ & $26.25 \mu \mathrm{s}$ & $23.8 \mu \mathrm{s}$ \\
\hline Resolution & $512 \times 128$ & $400 \times 112$ & $576 \times 224$ \\
\hline Light Source & & $450 \mathrm{~nm}$ LED & Xenon lamp \\
\hline Source Aperture & & $1 \mathrm{~mm}$ diaphragm & $1 \mathrm{~mm}$ diaphragm \\
\hline Stop Aperture & & none & $4 \mathrm{~mm}$ diaphragm \\
\hline
\end{tabular}

\section{1-D Transient Gas-Jet Mixing-Chemistry Model}

To aid in the interpretation of the experimental trends and to further probe the coupling between mixing and chemistry during end-ofinjection, a recently developed model, termed a 1-D transient gas-jet mixing-chemistry model, is used [22]. Building on recent

Page 4 of 18 developments of a 1-D transient gas-jet mixing model [23] that is capable of predicting jet quantities like penetration and mixture fraction, this new model adds chemistry predictions to each control volume. A graphical representation of this model is shown in Figure 3.

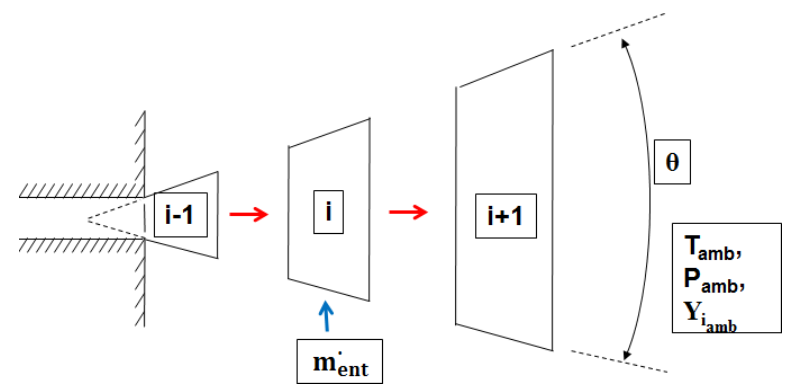

Figure 3 - 1-D transient gas-jet mixing-chemistry model. More details are found in [22].

The 1-D transient gas-jet mixing-chemistry model is composed of a series of discrete control volumes, positioned axially along the jet axis. The volume of each control volume is determined $a$ priori by a user-supplied constant spreading angle, $\theta$, of the jet. Fuel mass and momentum conservation equations are solved numerically in each control volume, $i$, to obtain the ambient entrainment rate, $m_{\mathrm{ent}}$, for an arbitrary injection profile. Then, to incorporate chemistry, species and energy conservations equations are solved for each control volume with the previously found ambient entrainment rate as an additional influx. For example, control volume i takes in mixtures from $\mathrm{i}-1$ and the ambient, as specified by the ambient entrainment rate. The mixture within control volume $i$ then undergoes adiabatic mixing and is allowed to react, at constant pressure, for the duration of the residence time. The control volume is considered a well-stirred reactor, i.e. no sub-grid turbulent combustion model is used. Note that simulations begin at start-of-injection and terminate $6 \mathrm{~ms}$ later thus capturing ignition as well as the possibility of combustion recession.

One key feature of the 1-D transient gas-jet mixing-chemistry model is that simultaneous mixing and chemistry can be realized. Mixing alone is not sufficient to understand complex ignition processes during transients, i.e. at the end-of-injection. Chemistry predictions are modeled with the aid of the reduced dodecane mechanism of Wang et al. [25], consisting of 100 species and 432 reactions. Predictions of mixture fraction and jet penetration agree reasonably well with experimental measurements of ECN Spray A and H [24]. Ignition is also reasonably well predicted for Spray H in Ref. [22]. While the fluid mechanics are highly simplified, this approach captures the main mixing features of the jet. Therefore, another key feature is that computational resources are reserved for comprehensive chemical mechanisms that would otherwise be intractable in higher-fidelity 2 or 3-D RANS and LES codes. While the model is capable of handling large chemical mechanisms, the large number of simulations performed prompted the use of a simplified mechanism.

\section{Description of Combustion Recession based on Measurements and 1-D Model}

Shown in Figure 4, are high-gain chemiluminescence and highsensitivity schlieren images acquired simultaneously during the same injection for a temperature variation on the Spray A condition. While these still images may be difficult to interpret with regards to 
Figure 4 - Simultaneously captured chemiluminescence and schlieren images of combustion recession for a temperature variation on the ECN Spray A condition. Images were acquired at Sandia.

aSORD shows pockets of ignition receding back towards the injector instead of a connected backward traveling wave. The pockets are also evident in the schlieren images, first at 463 us aSORD, which later merge as time progresses. Both diagnostics used are line-of-sight, so the observed ignition pockets at the $900 \mathrm{~K}$ ambient condition are indeed separated ignition sites. This transition from a sequential combustion recession at $1000 \mathrm{~K}$ to pockets of separated ignition sites at $900 \mathrm{~K}$ further suggests that the reactions under both conditions are driven by autoignition rather than flame propagation. Lastly, soot luminosity of burning dribble is again noticeable at $844 \mu$ s aSORD.

In contrast to the higher ambient temperature conditions, the $800 \mathrm{~K}$ condition shows no evidence of combustion recession in either the chemiluminescence or schlieren images. Also, because there is a lack of soot incandescence at this low ambient temperature, no Mie scatter from liquid droplets is observed near the injector at $-17 \mu$ s aSORD even through the injection event has not yet ended. Based on these images, it can be seen that ambient temperature plays a significant role in determining the likelihood of combustion recession.

In order to better understand the nature of combustion recession how each diagnostic may measure different features of the combustion recession process, the 1-D transient gas-jet mixing-chemistry model is employed in the following discussion. In the model, the rampdown process is modeled as a linear decrease of injection velocity with time that occurs over a duration of $100 \mu \mathrm{s}$, which is consistent with the experimentally measured ramp down duration for the injectors used in this study (see Figure 2).

While the inherent 1-D nature of the model prevents spatially accurate predictions of LOL, the trends of predicted ignition delay and LOL with ambient temperature are consistent with experimental results, as shown in Table 3. The results in Table 3 show that the 1-D model over-predicts LOL by $50-60 \%$ whereas ignition delays are over-predicted by $30-45 \%$. While ignition and lift-off processes are not uncoupled, accurate prediction of ignition processes are likely to be more important for capturing the physics of combustion recession. If this is the case, the better-matched ignition predictions provide motivation for the use of this model.

Table 3 - Comparison of experimental and model predicted ignition delays and flame lift-off lengths.

\begin{tabular}{|c|c|c|c|c|}
\hline $\begin{array}{c}\text { Ambient } \\
\text { temperature } \\
(\mathrm{K})\end{array}$ & $\begin{array}{c}\text { Exp. ignition } \\
\text { delay (ms) }\end{array}$ & $\begin{array}{c}\text { Model } \\
\text { ignition } \\
\text { delay }(\mathrm{ms})\end{array}$ & $\begin{array}{c}\text { Exp. flame } \\
\text { lift-off length } \\
(\mathrm{mm})\end{array}$ & $\begin{array}{c}\text { Model flame } \\
\text { lift-off } \\
\text { length (mm) }\end{array}$ \\
\hline 800 & 0.85 & 1.1 & 26.2 & 39 \\
\hline 900 & 0.44 & 0.65 & 16.5 & 28 \\
\hline 1000 & 0.24 & 0.35 & 12.2 & 19 \\
\hline
\end{tabular}

Figure 5 shows the time history of equivalence ratio and temperature from a computational cell within the jet located $10 \mathrm{~mm}$ from the injector, at four different ambient gas temperatures. This region is selected as a representative mixture volume within the near-nozzle region and lies upstream of the predicted LOL for all ambient temperature conditions. Note that this analysis does not track a parcel of reacting fuel along its path to ignition (Lagrangian perspective), but rather represents the progression of mixing and combustion within a region in space (Eulerian perspective). Also note that equivalence ratio is defined in the non-reacting sense by using the calculated mixture fraction and then quantifying the equivalence ratio based on the ambient oxygen concentration.

Throughout and after the end of injection, Figure 5 shows that the upstream jet mixtures progress through a series of entrainment and ignition processes that depend on the ambient gas temperature. Immediately aSORD, the jet volume at $10 \mathrm{~mm}$ begins entraining greater levels of hot ambient gases relative to the quasi-steady injection period, continuously decreasing the local equivalence ratio and raising its temperature until approximately 0.20 to $0.40 \mathrm{~ms}$ aSORD. Cool flame, or first-stage ignition, is then noticeable by the small, but sudden, bump in temperature to approximately 900 to $950 \mathrm{~K}$ (the exact time and temperature depends on ambient temperature). First-stage ignition occurs at higher equivalence ratios and earlier times aSORD for higher ambient temperatures. Hightemperature, or second-stage ignition, then occurs only for the 1000 and $950 \mathrm{~K}$ ambient temperature cases, as indicated by the rapid rise in temperatures above approximately $1500 \mathrm{~K}$. In addition, the equivalence ratio at second-stage ignition is closer to stoichiometric for the $1000 \mathrm{~K}$ ambient condition, resulting in a higher peak reaction temperature than for the $950 \mathrm{~K}$ ambient condition, where mixtures are much leaner by the time of second-stage ignition (near 0.5 ). Based on the trend in delayed second-stage ignition with decreasing ambient gas temperature, the upstream mixtures at this $10 \mathrm{~mm}$ location likely become too lean to support high-temperature ignition at later times aSORD, as indicated by a lack of second-stage ignition for the $900 \mathrm{~K}$ and $850 \mathrm{~K}$ ambient gas temperatures. Since the location of this small volume is upstream of the predicted LOL we can conclude that combustion recession to this axial location is not observed in the model for these conditions. By contrast, evidence of combustion recession for the $900 \mathrm{~K}$ ambient temperature condition is observed in the experimental images of Figure 4.

To investigate the discrepancy between the model and experiment, and also to further explore the nature of combustion recession, attention is focused on the modeled trends in combustion when transitioning from a higher ambient temperature environment to a lower temperature environment, under conditions where combustion recession reactions are still observed. For the modeled conditions, such a transition occurs when moving from a $1000 \mathrm{~K}$ ambient to a $950 \mathrm{~K}$ ambient temperature condition. Based on the predicted drop in peak reaction temperature when transitioning from the $1000 \mathrm{~K}$ to the $950 \mathrm{~K}$ ambient condition, we can expect a reduction in measureable reaction activity for a similar ambient temperature transition in the experiments. Consistent with this prediction, both a weaker chemiluminescence and a lower contrast in the schlieren images is observed in Figure 4 at $900 \mathrm{~K}$ compared to $1000 \mathrm{~K}$. 


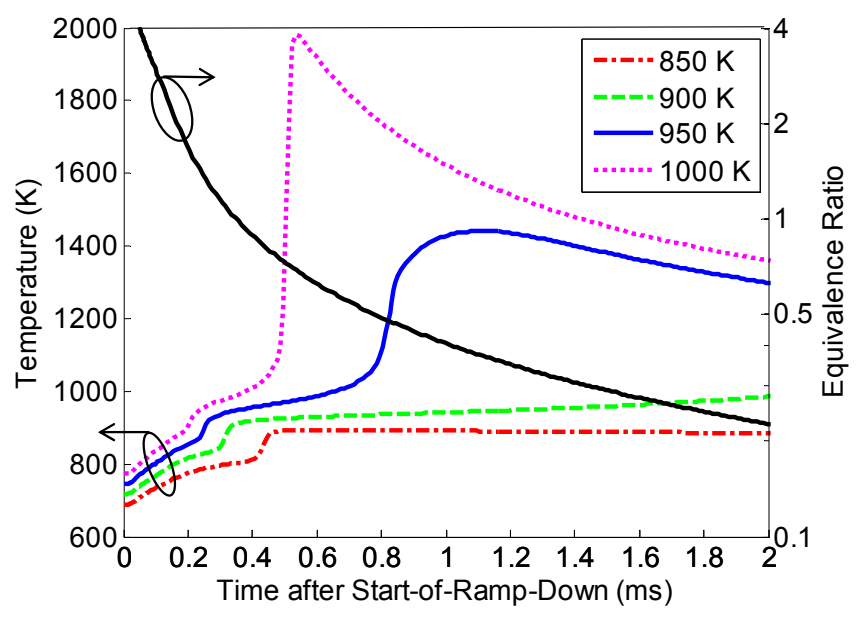

Figure 5 - Time history of model-predicted mixture states within the jet volume at $10 \mathrm{~mm}$ from the injector under an ambient temperature variation on Spray A conditions.

A major observation from Figure 4 is that higher ambient temperatures exhibit second-stage combustion recession while lower ambient temperatures did not. Also, this transition of combustion recession behavior appeared to be gradual, with ignition reactions becoming progressively weaker, as indicated by the chemiluminescence signal, as the ambient temperature was reduced. This observation was also consistent with the trend in predicted peak reaction temperatures in Figure 5. To further investigate why this trend exists, attention is again focused on the same small jet volume $10 \mathrm{~mm}$ from injector in Figure 6, which shows the progression of a "pseudo ignition delay" after start of ramp down. This pseudo ignition delay can be thought to represent the time evolution of the reactivity of these upstream mixtures as end-of-injection entrainment continuously leans these mixtures. The pseudo ignition delay at each time instance aSORD is determined by "freezing" the mixture and reaction state within the specified volume and allowing the mixture to react to completion, as if no further mixing occurs. The pseudo ignition delay is then taken as the time required for the mixture to reach a temperature of $1500 \mathrm{~K}$, which is representative of secondstage ignition.

In Figure 6, attention is focused on the $850 \mathrm{~K}$ condition first. As time after start-of-ramp-down initially progresses from $0 \mathrm{~ms}$ aSORD to about $0.2 \mathrm{~ms}$ aSORD, the mixture becomes hotter and more fuel lean (approaching stoichiometric, shown as a triangle symbol), and thus the pseudo ignition delay shortens. Near $0.2 \mathrm{~ms}$ aSORD, the volume is at its most-reactive state, as evidenced by the minimum in pseudo ignition delay at this time. Figure 5 further shows that equivalence ratios at this minimum in the pseudo ignition delay for each ambient temperature condition are between 1.0 and 2.0, with higher ambient temperature conditions exhibiting this minimum at earlier times and at the higher end of this equivalence ratio range. Typical closed batch reactor calculations of adiabatically-mixed fuel-ambient exhibit an ignition delay minimum at equivalence ratios between 1.0 and 2.0, depending on conditions, and the mixture state at this point is often referred to as the most-reactive mixture fraction [29]. However, for the $850 \mathrm{~K}$ ambient case, first-stage ignition does not occur until $0.45 \mathrm{~ms}$ (denoted with a closed circle in Figure 6), and by this time, the mixture has a continuously increasing pseudo ignition delay such that second-stage ignition of these mixtures cannot occur with increasing time aSORD.

Page 7 of 18
Similar to the $850 \mathrm{~K}$ condition, for the $950 \mathrm{~K}$ condition, the mixture becomes hotter and more fuel lean as time after start-of-ramp-down progresses, and thus the pseudo ignition delay shortens. Differently from the $850 \mathrm{~K}$ condition though, significant ignition intermediates are transported into or generated by $0.2 \mathrm{~ms}$ aSORD as indicated by first stage ignition (denoted with a closed circle in Figure 6). Therefore, the pseudo ignition delay decreases as second stage ignition slowly occurs thereafter, leading to a condition that supports second-stage ignition of these mixtures and combustion recession.

Figure 6 shows that the rate at which the ignition delay of a mixture changes in time, $d \tau / d t$, determines whether or not second-stage ignition can occur with increasing time aSORD. If the rate at which the ignition delay changes is faster than unity, $\frac{d \tau}{d t}>1$, second-stage ignition is not possible. This analysis is useful because it incorporates the transport and generation of ignition intermediates into the interpretation of combustion recession likelihood at a specific location. Due to the observed joint effects of the time-dependent evolution of mixing and chemistry intermediates, analysis based primarily on the time-dependent mixing behavior of upstream mixtures, such as that demonstrated by Figure 5, are not sufficient to fully describe the behavior of combustion recession.

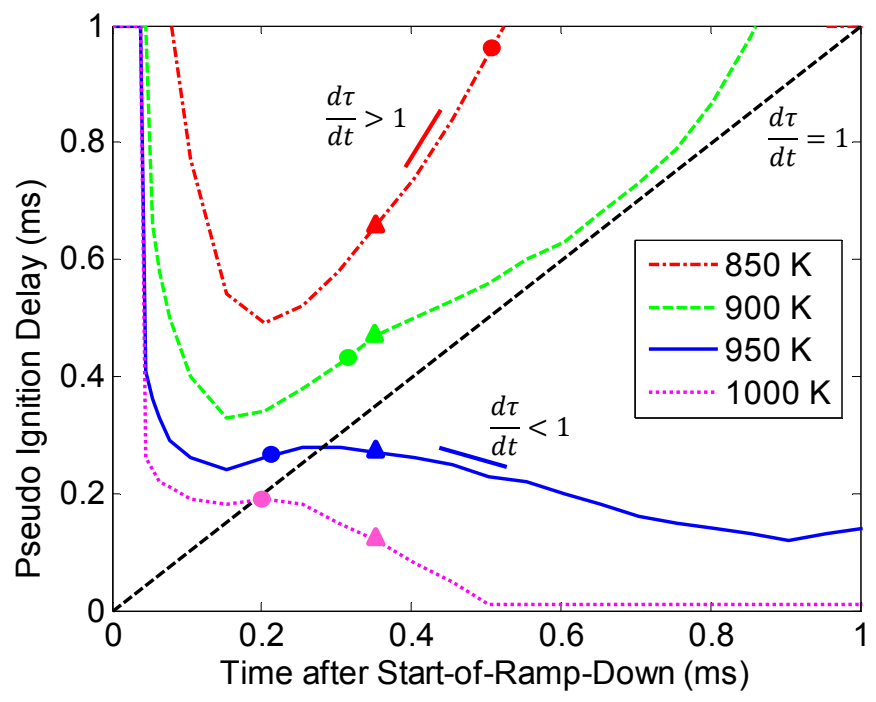

Figure 6 - Model-predicted pseudo-ignition delay of the jet volume at $10 \mathrm{~mm}$ from injector. Pseudo ignition delay is the time required for ignition at each instance in time as if no more mixing could occur. Triangle symbols denote a stoichiometric mixture while circle symbols denote first-stage ignition.

Recall that under certain conditions, combustion recession is not observed to behave as a backward-traveling wave, but rather as separated pockets of ignition that merge over time, like that of the 900 K Spray A condition in Figure 4. Similar to the 900 K Spray A condition, Figure 7 demonstrates an experimentally observed combustion recession event with separated ignition pockets, but with lower background schlieren noise such that the separated ignition pockets can be more easily observed. Note that the conditions of Figure 7 are under a higher ambient oxygen concentration and with a different fuel compared to Figure 4. The schlieren images of Figure 7 show high temperature products generated in pockets at $452 \mu \mathrm{s}$ aSORD, as indicated by a strong darkening of the schlieren image in isolate pockets upstream of the lift-off-length position. These separated pockets of high temperature products slowly merge by 929 $\mu \mathrm{s}$ aSORD. These isolated ignition pockets may be due to the turbulent mixing field, but as further discussed later, the end-of- 
injection entrainment wave may also contribute to discontinuities in the mixture field.

Figure 7 also shows that the time required for ignition to reach the injector is longer than for the $900 \mathrm{~K}$ Spray A condition in Figure 4. This is likely due to the use of a lower reactivity fuel (n-heptane) in these experiments, compared to dodecane for the Spray A condition. Indeed, Figure 4 and Figure 7 show that the behavior of combustion recession changes with either a change in fuel reactivity or ambient temperature, which both serve to change the ignition delay of a given mixture in the same fashion. Hence, lower reactivity fuel should have a similar effect on combustion recession as reduced temperature, i.e. transitioning from $1000 \mathrm{~K}$ to $900 \mathrm{~K}$. Attention is focused on how the ambient temperature changes the behavior of combustion recession in Figure 8.

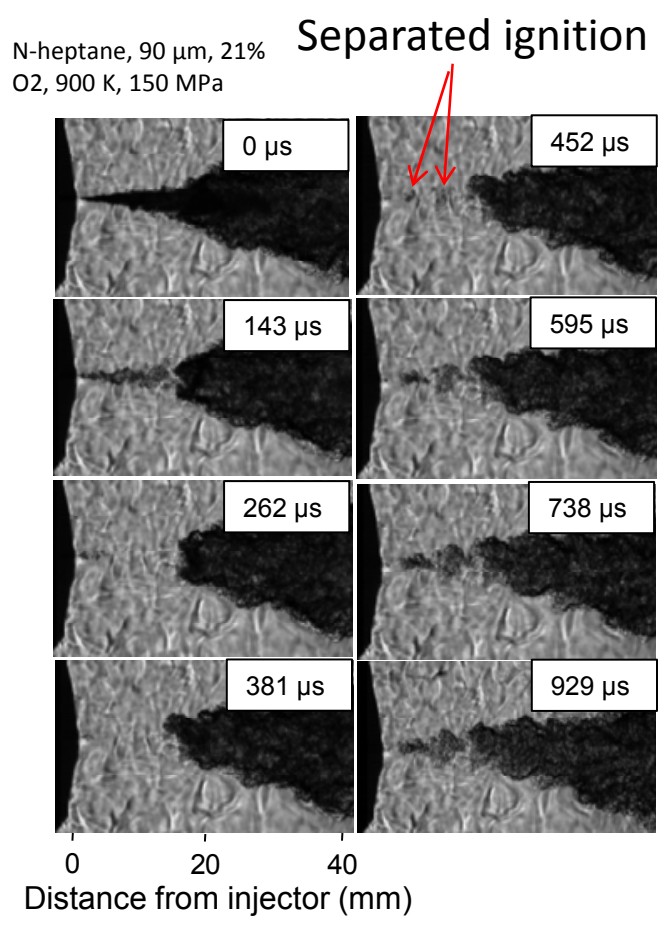

Figure 7 - Experimental evidence of separated or "pockets" of ignition that merge later in time. Time stamps on each image are after end-of-injection. Images were acquired at CMT.

To further validate the predicted trends in combustion recession with the 1-D model, and further explore the occurrence of separated ignition pockets during combustion recession, the time to ignition aSORD is plotted in Figure 8, providing an understanding of when each mixture along the axis of the injector reaches second stage ignition. Note that Figure 8 plots the actual model-predicted time to second-stage ignition during and after the simulated end-of-injection transient, not a "frozen" or pseudo ignition delay like that shown in Figure 6. As before, the time to ignition is defined as the time required for the volume at each axial location to reach $1500 \mathrm{~K}$. The model predicted LOL is indicated in this plot by the location where the time to ignition approaches zero, since this location has already reached second-stage ignition at $0 \mu \mathrm{s}$ aSORD.

In Figure 8, the model predicts that higher ambient temperatures produce a backward traveling wave of ignition similar to the experimental images of Figure 4, as indicated by a sequentially increasing ignition delay time moving from the lift-off-length location to the injector. This behavior is termed sequential ignition in the current work. For the $1050 \mathrm{~K}$ case, ignition propagates from 17 $\mathrm{mm}$ at $0 \mu \mathrm{s}$ to $15 \mathrm{~mm}$ by $200 \mu \mathrm{s}$, then to $10 \mathrm{~mm}$ by $350 \mu \mathrm{s}$, and finally to the injector $(0 \mathrm{~mm})$ by $450 \mu \mathrm{s}$. However, as ambient temperature is decreased to $975 \mathrm{~K}$ and $950 \mathrm{~K}$, sequential ignition is no longer observed. While second-stage ignition is already occurring near 22 $\mathrm{mm}$ from the injector, mixtures near 5-7 $\mathrm{mm}$ ignite at approximately $600 \mu \mathrm{s}$ aSORD for the $975 \mathrm{~K}$ case and at approximately $900 \mu \mathrm{s}$ aSORD for the $950 \mathrm{~K}$ case, well before adjacent locations within the upstream mixtures of the jet. For the $975 \mathrm{~K}$ case, the ignition at $7 \mathrm{~mm}$ then spreads upstream and downstream by about $700 \mu$ aSORD. As ambient temperature is further reduced to $950 \mathrm{~K}$, much longer times to ignition are observed on either side of the separated ignition site, indicating the potential for partial combustion recession under certain conditions. These model predictions are consistent with the schlieren images of Figure 4 and Figure 7 in capturing a transition from sequential to separated combustion recession as conditions are changed from more to less reactive.

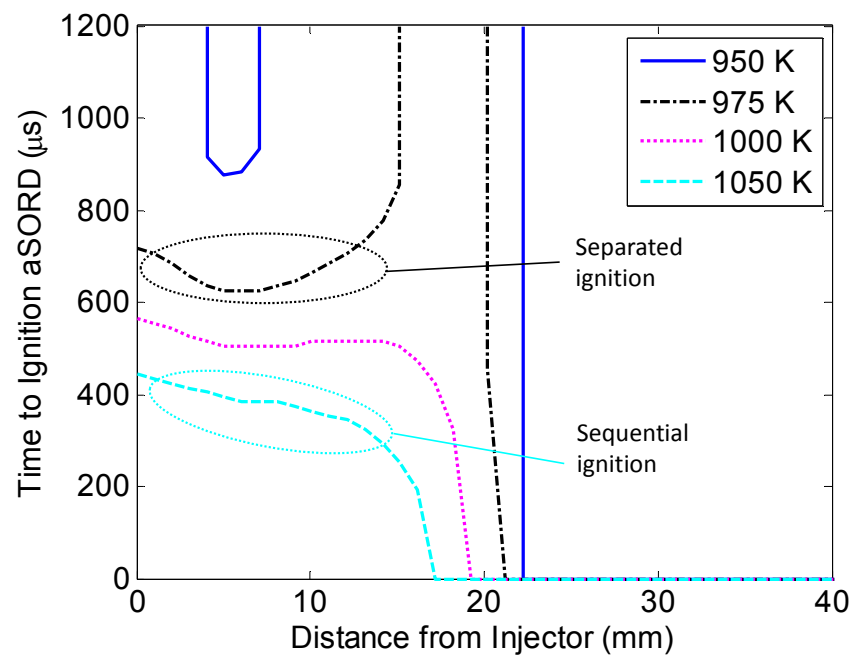

Figure 8 - Spatial information of combustion recession for various ambient temperatures. Time to ignition is defined in text.

Evidence from Figures 4 and 8 and the corresponding discussion indicate that combustion recession may be dominated by ignition rather than flame propagation processes. Under a high ambient temperature of $1000 \mathrm{~K}$, Figure 4 demonstrated that combustion recession appears as a connected, backward-traveling wave possibly driven by flame propagation processes. But, the speed of combustion recession for this condition is approximately $200 \mathrm{~m} / \mathrm{s}$ and is much faster than gas-turbine studies that measured flashback speeds on the order of typical turbulent flame speeds [30, 31]. Furthermore, as the ambient temperature was reduced to $900 \mathrm{~K}$ in Figure 4, combustion recession appeared as isolated ignition sites that merged with time, which is inconsistent with the concept of a propagating flame sheet. Additionally, the 1-D model, which is only capable of modeling autoignition, reproduced the combustion recession behavioral transition of a backward traveling wave to isolated ignition sites in Figure 8 . 


\section{Effect of Ambient and Fuel Injection Conditions on Combustion Recession}

In order to further characterize the behavior of experimentally observed combustion recession in a meaningful manner, and its response to a broader range in ambient and fuel injection conditions, the time it takes for ignition to occur at the injector, i.e. time to ignition, is compared and analyzed in this section for a wide range of measurements. Time to ignition is defined as the time aSORD required for high-temperature ignition to occur at a position very close to the nozzle ( $\sim 2-3 \mathrm{~mm}$ from the injector). This metric is relevant to engines because the time required for combustion recession must not be excessively long if UHC control is to be realized.

\section{Effect of Ambient Temperature}

Shown in Figure 9 is the ambient temperature dependence of time-toignition aSORD for a range of ambient/injection conditions. The left most data point for each condition represents a boundary for the lowest ambient temperature where combustion recession is observed. Notice that this boundary is specific to the ambient/injection condition. In general, the trend of increasing time to ignition as ambient temperature is decreased is consistent with that expected from an isolated mixture standpoint, whereby ignition delay times scale with reactant mixture temperature. Furthermore, from a diesel injection viewpoint or Lagrangian perspective of the end-of-injection mixing process, this trend is also consistent. For a parcel of fuel exiting the injector towards the end of ramp down, low injection velocities will mean that the last injected fuel parcels will remain close to the injector and be mixed relatively rapidly with hot ambient gases to maintain continuity within the jet. With identical mixing rates between different ambient temperature conditions, entrainment of lower temperature ambient gases does not produce ignition precursors as quickly as entrainment of high temperature ambient gases and thus ignition is expected to occur later.

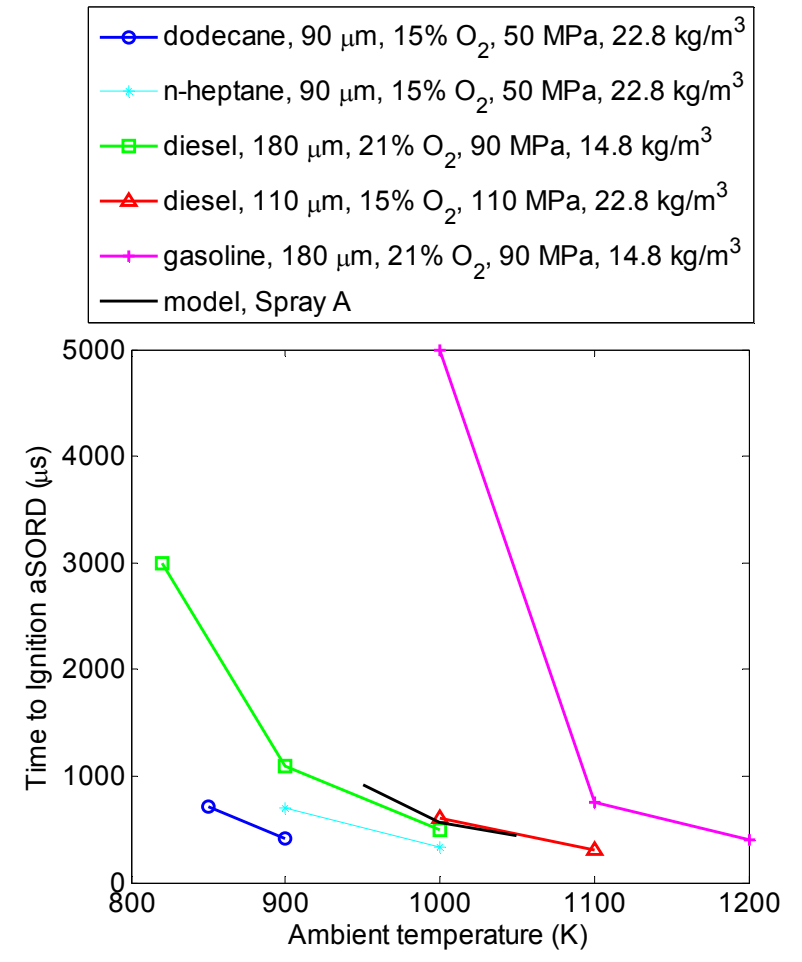

Figure 9 - Experimental and model predicted dependence of combustion recession on ambient temperature

\section{Effect of Ambient Oxygen}

The effect of ambient oxygen concentration is demonstrated in Figure 10. Again, the left most data point for each condition represents a boundary for the lowest ambient oxygen concentration where combustion recession is observed and is specific to the ambient/injection condition. From an isolated mixture standpoint, the trend of increasing time to ignition as ambient oxygen concentration is decreased is consistent with expectations. From a Lagrangian perspective, longer ignition times for lower oxygen concentrations is also consistent with expectations because it takes longer for the last parcels of injected fuel to mix to a given oxygen concentration at lower ambient oxygen concentrations, given identical mixing rates.

Uncertainty bars, for the condition with n-heptane as the fuel, are also provided in Figure 10 to provide a sense of the relative magnitude of the oxygen concentration effect relative to injection-to-injection dispersion. Fifteen separate injections were performed to obtain the mean time to ignition aSORD for this case. The uncertainty bars represent uncertainty in the mean with a $95 \%$ confidence interval for this condition. Estimation of uncertainty is this manner is expected to underestimate the uncertainty for the other data points shown because they are single realizations. 


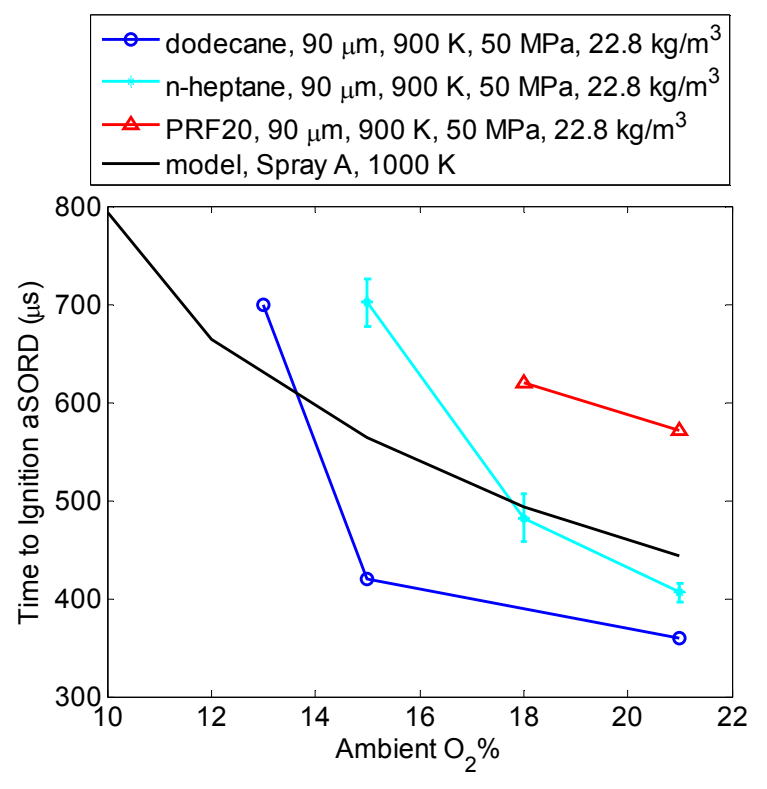

Figure 10 - Experimental and model-predicted dependence of combustion recession on ambient oxygen concentration

To better understand the effect of ambient oxygen on the time to ignition, the temperature and equivalence ratio within the jet volume at $10 \mathrm{~mm}$ from the injector is shown in Figure 11. First-stage ignition within this volume occurs close to $0.2 \mathrm{~ms}$ aSORD for a $21 \% \mathrm{O}_{2}$ environment, with increasing times aSORD for lower ambient $\mathrm{O}_{2}$ conditions. First-stage ignition also occurs in richer mixtures for lower ambient oxygen conditions. For example, the mixture has reached $\phi=2.3$ at first-stage ignition for the $10 \% \mathrm{O}_{2}$ ambient condition, while it approaches stoichiometric for higher ambient oxygen conditions, reaching $\phi=1.1$ for $21 \% \mathrm{O}_{2}$. Second-stage ignition also occurs later for decreasing ambient $\mathrm{O}_{2}$ conditions, but at nearly the same equivalence ratio. This observation is consistent with those from typical diesel-like injections [33]. Note that the mixture fraction distribution is the same between all ambient $\mathrm{O}_{2}$ conditions. Recall that the equivalence ratios differ because the stoichiometric air-fuel ratio increases with decreasing ambient $\mathrm{O}_{2}$. Lastly, predicted peak ignition temperatures are consistent with expectations based on an isolated reacting mixture.

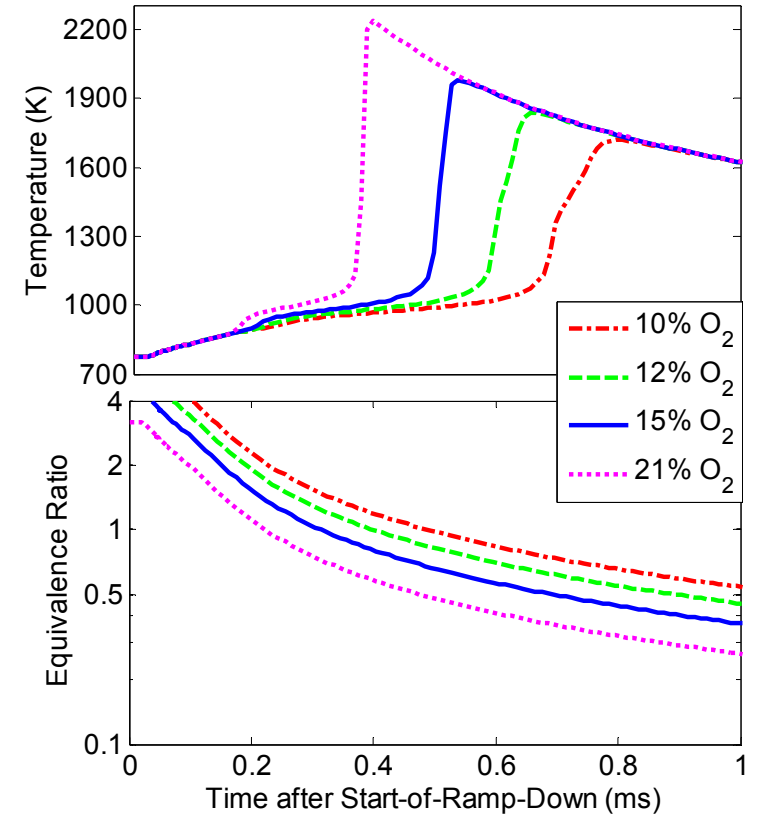

Figure 11 - Model predicted time history of the jet volume at $10 \mathrm{~mm}$ from the injector under an ambient oxygen concentration variation on Spray A (ambient temperature $=1000 \mathrm{~K})$ conditions.

Much like the ambient temperature variation shown in Figure 8, a transition from sequential to separated combustion recession is also observed in Figure 12 for varying ambient oxygen concentration. Essentially, combustion recession behaves as a series of sequential ignition sites at more reactive conditions, and as separated ignition sites at less reactive conditions. For the less reactive $10 \%$ ambient $\mathrm{O}_{2}$ condition, the first location to ignite (other than the already burning mixture at the LOL of $24 \mathrm{~mm}$ ) is a "pocket" surrounding $7 \mathrm{~mm}$ from the injector. Between 4 and $9 \mathrm{~mm}$, the time to ignition is nominally uniform meaning that this entire region will ignite at the same time. An additional feature at this low ambient $\mathrm{O}_{2}$ condition is that there is a region between 14 and $22 \mathrm{~mm}$ that does not ignite. The time to ignition in this region exceeds that of the simulation $(6 \mathrm{~ms})$. Both the ignition "pocket" at $7 \mathrm{~mm}$ and lack of ignition between 14 and 22 $\mathrm{mm}$ is very similar to the behavior of the $975 \mathrm{~K}$ condition in Figure 8.

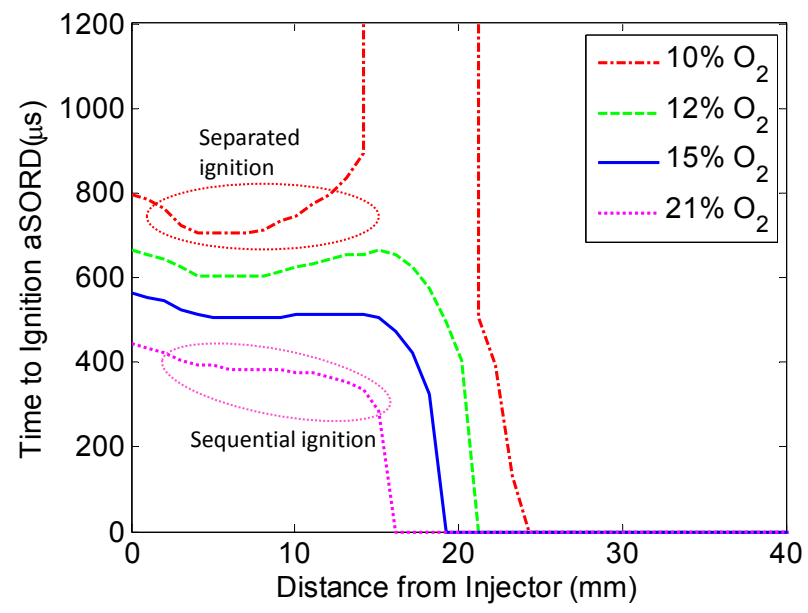


Figure 12 - Model predicted spatial information of combustion recession for various ambient oxygen concentrations. Model inputs are Spray A conditions with ambient temperature $=1000 \mathrm{~K}$. Time to ignition is defined in text.

\section{Effect of Injection Pressure}

In the previous discussion, ambient temperature and $\mathrm{O}_{2}$ were shown to affect the chemistry of combustion recession, under identical mixing conditions during end-of-injection, in a manner that was expected from the known ignition behavior of isolated mixtures. In this section, injection pressure is varied in order to observe the effect of different end-of-injection mixing rates on combustion recession. Possibly unique to the employed injector hardware, the ramp-down duration is identical, $100 \mu \mathrm{s}$, for all injection pressures tested.

The time aSORD to ignition at the injector slightly increases with injection pressure for the majority of the data collected in Figure 13. Interestingly, the ignition delay for a typical diesel injection slightly decreases with increasing injection pressure, opposite to combustion recession trend [32]. Decreasing ignition delays are suggested to occur because the higher injection pressures enhance mixing rates and thus entrain more hot ambient gases leading to quicker ignition [34]. One condition does exhibit a decreasing trend with injection pressure though, namely the dodecane, $90 \mu \mathrm{m}, 21 \% \mathrm{O}_{2}, 900 \mathrm{~K}, 22.8$ $\mathrm{kg} / \mathrm{m}^{3}$ condition. The observed trend for this condition may be due to under-mixing as typical for diesel ignition delay, because the condition has a short LOL (approximately 10-12 $\mathrm{mm}$ from the injector) where fuel-rich conditions are expected, while all other conditions may be over-mixed aSORD.

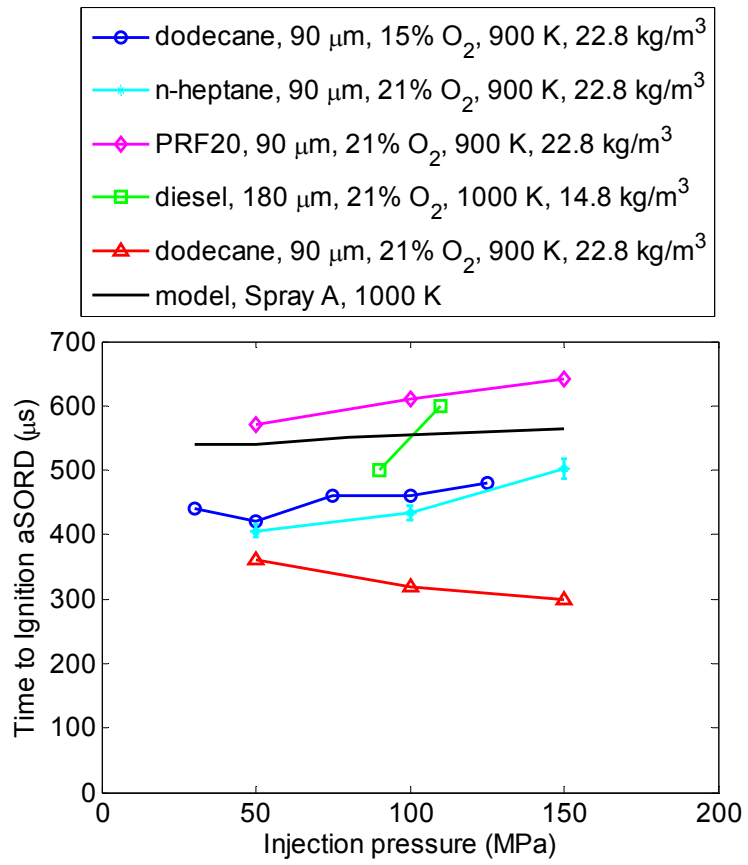

Figure 13 - Experimental and model-predicted dependence of combustion recession on injection pressure

The 1-D transient gas-jet mixing-chemistry model is used to investigate why the combustion recession trend in Figure 13 is opposite to a typical diesel injection ignition delay trend with injection pressure. Again, attention is given to a small volume within the jet at $10 \mathrm{~mm}$ from the injector as the region of interest in Figure 14. The top portion of Figure 14 demonstrates that second-stage ignition occurs earlier for lower injection pressures and also at more fuel-rich conditions. The bottom portion of Figure 14 is a zoomed section of the top plot such that the details of the transition from firstto second-stage ignition are more clear.

Figure 14 shows that the entrainment wave reaches the $10 \mathrm{~mm}$ axial location first for the highest injection pressure of $150 \mathrm{MPa}$. This is evidenced by the steady increase in temperature accompanying more rapid ambient entrainment, which is enabled by the faster moving entrainment wave for this high injection pressure condition. Firststage ignition then appears at the same time for all injection pressure conditions, but second-stage ignition occurs first for the lowest injection pressure condition. The more rapid entrainment leads to mixtures that are below stoichiometric near the end of first-stage ignition, which inhibits the transition to second-stage ignition relative to lower injection pressure conditions which remain closer to stoichiometric near the end of first-stage ignition. Indeed, the dwell between first- and second-stage ignition has been shown to be more dependent on equivalence ratio, given a constant ambient oxygen concentration, than temperature [35]. As such, more fuel rich mixtures, albeit at a slightly lower temperature, will transition to second stage ignition before more fuel-lean, and thus slightly hotter mixtures.

The experimental condition that exhibited an opposite trend to the rest of the data in Figure 13 was also modeled (with both $900 \mathrm{~K}$ and $1000 \mathrm{~K}$ ambient temperature), but the trend was not reproducible. The inability to capture this trend is likely due to the 1-D nature of the model, i.e. since the radial distribution is cross-sectionally averaged. The radial distribution is more important for capturing the combustion behavior at the flame lift-off length for conditions that are under-mixed and less important for over-mixed conditions. Indeed, for over-mixed conditions, the ignition delay distribution along the radial direction at the LOL location is much more uniform compared to under-mixed conditions and thus the cross-sectionally averaged approach used within the 1-D model is more reasonable.

Page 11 of 18 

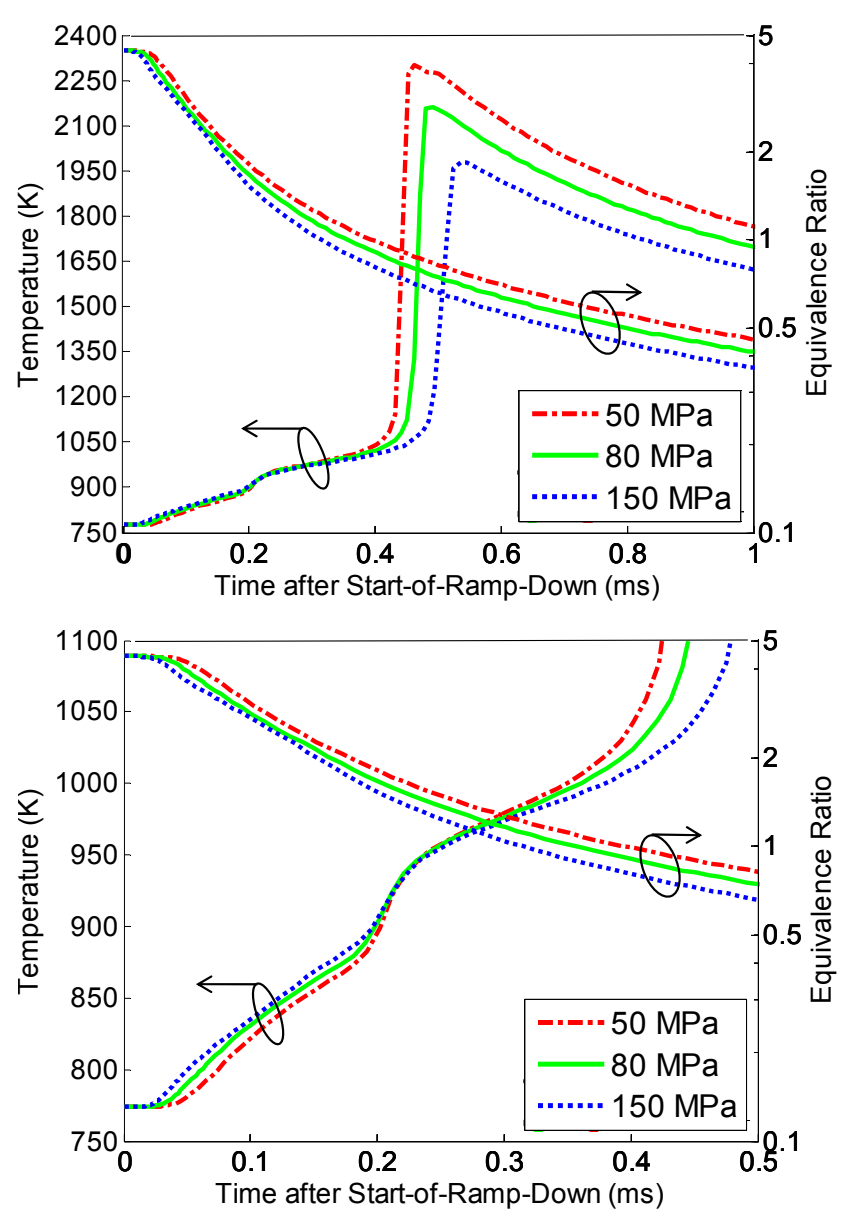

Figure 14 - Time history of model-predicted mixture states within the jet volume at $10 \mathrm{~mm}$ from the injector under an injection pressure variation on Spray A (ambient temperature $=1000 \mathrm{~K}$ ) conditions.

\section{Discussion}

As demonstrated in the current work, combustion recession is dependent on several mixing and chemistry-dependent parameters and is thus a complex path-dependent process. At the very least it is instructive, and useful to engine designers, to be able to predict whether or not combustion recession will occur under certain operating conditions in order to better understand the potential for control of lean-source near-nozzle unburned hydrocarbon emissions. As a first step towards this goal, an over-arching observation from the previous section is that combustion recession is less likely for less reactive conditions. In particular, the time required for mixtures near the injector nozzle to reach second-stage ignition increased for lesser reactive conditions, until combustion recession was no longer observed. However, similar statements can be made for the stabilization of flame lift-off length (LOL) itself during the steady period of injection. More reactive fuels and higher ambient temperatures or oxygen concentrations result in shorter LOLs for the same nozzle and injection pressure [32]. As a result, the mixture equivalence ratio at the LOL increases for these more reactive conditions. Likewise, low injection pressure conditions have slower mixing rates and shorter LOLs, also resulting in higher equivalence ratios at the LOL. But it is not clear if the co-dependency of mixing and chemistry that determines LOL during steady injection would also apply for combustion recession since the way in which the mixing field evolves aSORD is dependent upon other factors. For example, is the likelihood of combustion recession correlated simply to the initial mixture, as expressed as the equivalence ratio at the LOL, or to what degree will it depend upon mixing rate as affected by ramp-down shape? There may be a dominating relationship between the mixture equivalence ratio at the steady LOL, as a measure of the mixing and chemistry terms that determine reactivity, and the existence of combustion recession.

To investigate this hypothesis, the experimental cross-sectionally averaged equivalence ratio at the LOL is plotted in Figure 15. The abscissa, $\mathrm{D}_{\mathrm{eff}} /\left(\alpha \mathrm{U}_{\mathrm{eff}}\right)$, is a dimensionless parameter that incorporates all three terms that are known to affect the behavior of the end-ofinjection entrainment wave [9]. Thus, Figure 15 attempts to relate the end-of-injection process to the equivalence ratio at an igniting mixture (i.e. at the flame LOL). The effective orifice diameter, $D_{\text {eff }}$, influences both the speed and peak relative entrainment rate, also referred to as the magnitude of the entrainment wave. The rampdown duration, $\alpha$, also affects the magnitude of the entrainment wave. For instance, a longer $\alpha$ lowers the peak relative entrainment rate, maintaining richer mixtures near the injector for longer. Lastly, the injection velocity, $U_{\text {eff }}$, controls the speed of the entrainment wave. A detailed discussion of how this dimensionless parameter is obtained and the physics driving its use are shown in the next section.

The cross-sectionally averaged equivalence ratio at the LOL for each condition was obtained with the correlation provided by Ref. [36]. Inputs to the correlation are the fuel/ambient densities, desired axial location (in this case, the flame LOL), the effective orifice diameter and the spray spreading angle. As recommended in Ref. [24], the spray spreading angle (which is an input to the equivalence ratio correlation in Ref. [24]) was adjusted to match the vapor penetration data using the 1-D model. This process enables a more robust input of the spreading angle because direct optical measurement is sensitive to the employed technique resulting in large uncertainties of the spreading angle [24].

Figure 15 demonstrates that the existence of combustion recession seems indeed to be related to the equivalence ratio at the flame LOL. Each symbol is colored according to whether or not combustion recession is observed. The color green indicates definite observation of combustion recession, blue denotes partial combustion recession, and red symbolizes no combustion recession observed. For each fuel, there appears to be boundary of $\phi(\mathrm{LOL})$ for which combustion recession is no longer observed. The value of this boundary is dependent on the type of fuel used but is in the range of 1-3. Note that the data in Figure 15 spans a wide range of ambient temperatures, ambient oxygen concentrations, and a modest range of ambient densities, yet a clear $\phi(\mathrm{LOL})$ boundary appears to exist. In other words, there is no overlap of red and green symbols.

Unfortunately, the dependence of this boundary as a function of the dimensionless end-of-injection parameter, $\mathrm{D}_{\text {eff }} /\left(\alpha \mathrm{U}_{\text {eff }}\right)$, cannot be established from the experimental data. The data is rather sparse in certain locations, and the shape of the ramp-down is essentially the same for all conditions as only a single ramp-down duration could be generated with the solenoid-actuated injectors used in the data collection for this study. This motivates the need for more data to properly define the dependency upon $\mathrm{D}_{\text {eff }} /\left(\alpha \mathrm{U}_{\text {eff }}\right)$ if a larger range of diameters, injection pressures, and ramp-down durations can be generated. Further motivation for the use of this dimensionless parameter in determining the likelihood is demonstrated in the following section.

Page 12 of 18 


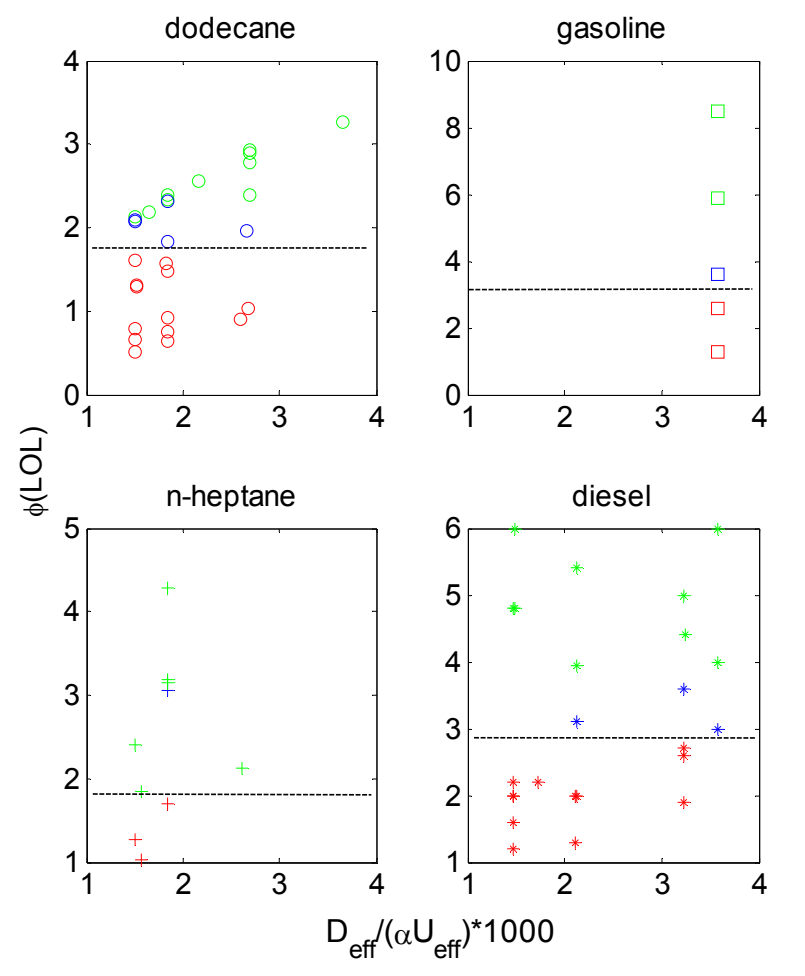

Figure 15 - Identification of a boundary (shown with a dashed line) for the existence of combustion recession based on experimental cross-sectionally averaged equivalence ratio at the lift-off length for a variety of fuels and conditions. The color green indicates combustion recession, blue denotes partial combustion recession while red symbolizes no combustion recession

To investigate the physical drivers for an equivalence ratio dependence on the likelihood for combustion recession, the predicted time history of the mixture field after the end of injection, with the 1D mixing-chemistry model, is demonstrated in Figure 16. Two different end-of-injection ramp-down durations are considered to observe how the equivalence ratio changes aSORD near the location of the flame lift-off length. Essentially, Figure 16 demonstrates the cumulative effect of the entrainment wave on the mixture field. For the fast ramp down condition in the top portion of the figure, there appears to be a unique time aSORD and axial location where the equivalence ratio changes most rapidly, such that a "kink" in the axial equivalence ratio decay is observed. This kink, which arises at 20 $\mathrm{mm}$ from the injector $100 \mu \mathrm{s}$ aSORD, is termed the saddle point location. Downstream of this saddle point location, the equivalence ratio no longer follows the steady-injection profile decay of $\sim 1 / x$. Indeed, the equivalence ratio actually increases downstream of this point until the steady jet solution is recovered downstream of the leading edge of the entrainment wave at $25 \mathrm{~mm}$. The timing of this saddle point occurrence is coincident with the end of ramp down, or complete end of injection, at $100 \mu$ s aSORD. Similarly, for the slower ramp down condition modeled in the lower portion of Figure 16, a saddle point is also observed, but at much later time aSORD and at a location much further downstream than that for the fast ramp down condition. Again, the timing at which the saddle point arises in the mixture decay corresponds to the time at end of ramp down, which is $550 \mu$ s aSORD for the slow ramp down case. Mixtures also clearly remain more fuel rich closer to the nozzle, at a given time aSORD, for this slower ramp down condition.
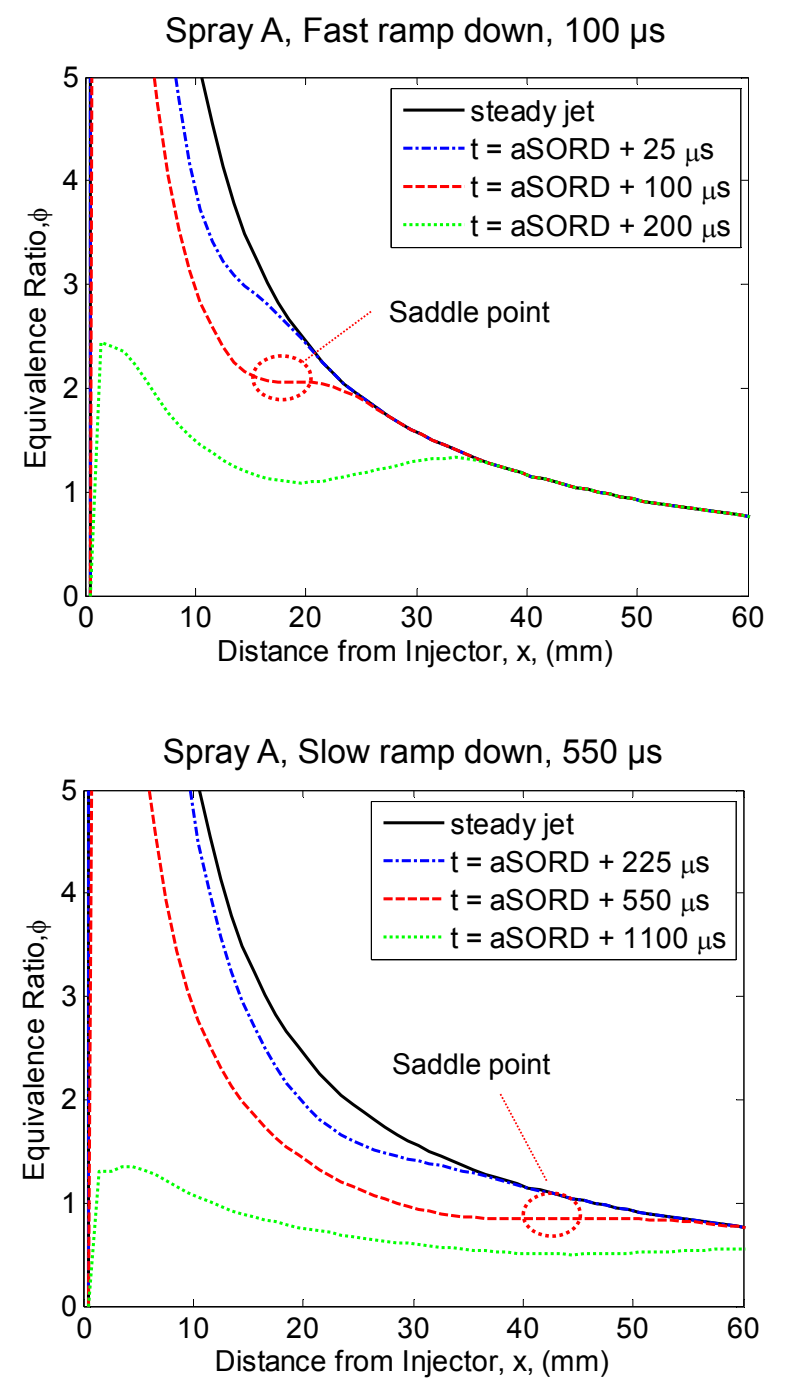

Figure 16 - Time history of the mixture fields for two end-of-injection profiles. Fast ramp down - $100 \mu$ s duration. Slow ramp down $-550 \mu$ s duration

Physically, the saddle point represents the portion of the mixture that experiences the greatest rate of change during the injection ramp down, relative to its value during the steady-state period of injection. A mathematical expression of this statement is given as:

max. relative time rate of change of $\Phi=$

$$
\frac{1}{\Phi_{\text {steady }}(x)} \max \left(\frac{\partial \Phi(x, t)}{\partial t}\right) .
$$

Shown in Figure 17 is a graphical representation of this concept, where the local maxima are coincident with the previously identified saddle point locations for each ramp down duration. While the mixture field closest to the injector is rapidly changing, making it less intuitive to predict how or if combustion recession may occur, the saddle point arises at a single location that may prove useful in analyzing the likelihood for combustion recession to transition across such mixtures. Since this location represents the portion of the jet that experiences the greatest relative dilution rate, it is also the most likely to experience over-mixing, and thus unable to support second-stage ignition reactions. 


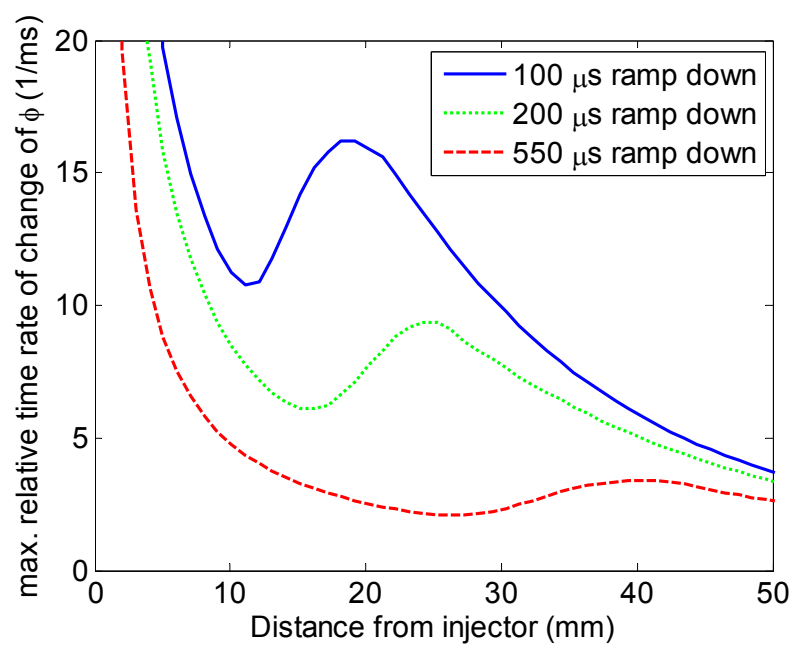

Figure 17 - Map of how quickly mixtures are affected by the entrainment wave relative to their value during steady injection. Saddle points represent locations that are most likely to over-mix.

Characteristics of the entrainment wave, namely the magnitude and speed, have already been shown to be a function of effective diameter, ramp-down duration, and the injection velocity [9]. Extending these findings to the effect of the entrainment wave on the mixture field demonstrates that these three parameters do indeed control the saddle point location, $\beta$, shown in Figure 18. As previously demonstrated in Figure 16, for longer ramp down durations at a fixed injection pressure and nozzle diameter, $\beta$ moves downstream. The same trend is further observed for higher injection pressures (velocities) and nozzle diameters for a fixed ramp-down duration.

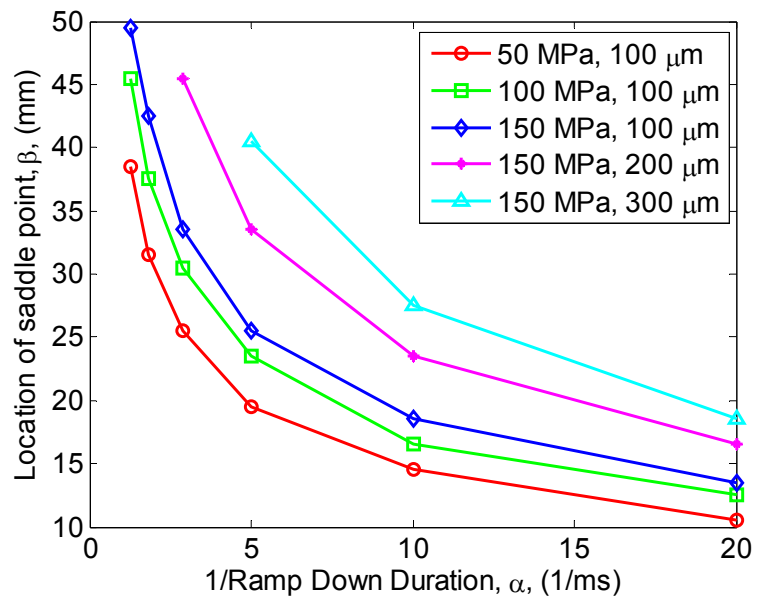

Figure 18 - Effect of injection parameters on the saddle point

If $\beta$ is normalized by the effective orifice diameter and the rampdown duration is normalized by the effective diameter and effective velocity, a collapse of the predicted saddle point location is revealed and shown in Figure 19. The ordinate, $\beta / \mathrm{D}_{\text {eff }}$, is therefore the nondimensional location that experiences the greatest relative dilution rate. Thus, a mixture at this location is likely to over-mix and either partially ignite or fail to ignite altogether. If the mixture is already burning, it may extinguish. Of course, there exists a competition between the kinetic rate-inhibiting effects of dilution and the rate-

Page 14 of 18 enhancing effects of the high ambient temperature. An appropriate non-dimensional location for this mixture is therefore required to relate to the non-dimensional saddle point location, $\beta / \mathrm{D}_{\text {eff. }}$.

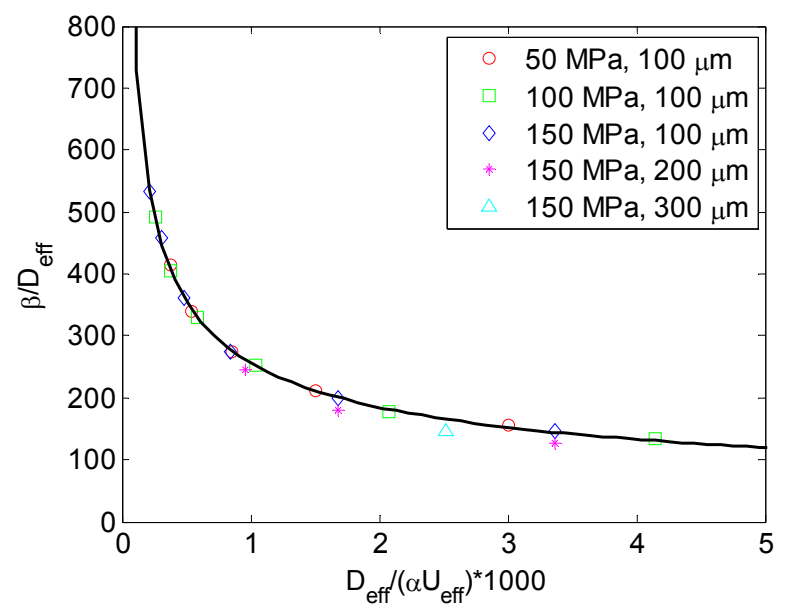

Figure 19 - Normalized saddle point location as a function of injection conditions, namely the injection pressure, nozzle diameter and ramp down duration.

If the LOL is chosen as the appropriate mixture location and normalized by the effective orifice diameter, the normalized saddle point location provides an excellent boundary for the observed existence of combustion recession for both experiments and 1-D model predictions in the top portion of Figure 20. Note that model predictions (triangle symbols) are shown in an attempt to fill in operating condition gaps of the experimental data (circle symbols). The experimental data in this figure includes a large operating parameter sweep, shown in Table 1, using dodecane as the fuel. To create the spread in model predictions, the following parameters were varied: ambient oxygen concentration from $10-21 \%$, ambient temperature from $850 \mathrm{~K}$ to $1100 \mathrm{~K}$, ramp down duration from $40 \mu \mathrm{s}$ to $800 \mu \mathrm{s}$, and the orifice diameter from $90 \mu \mathrm{m}$ to $200 \mu \mathrm{m}$.

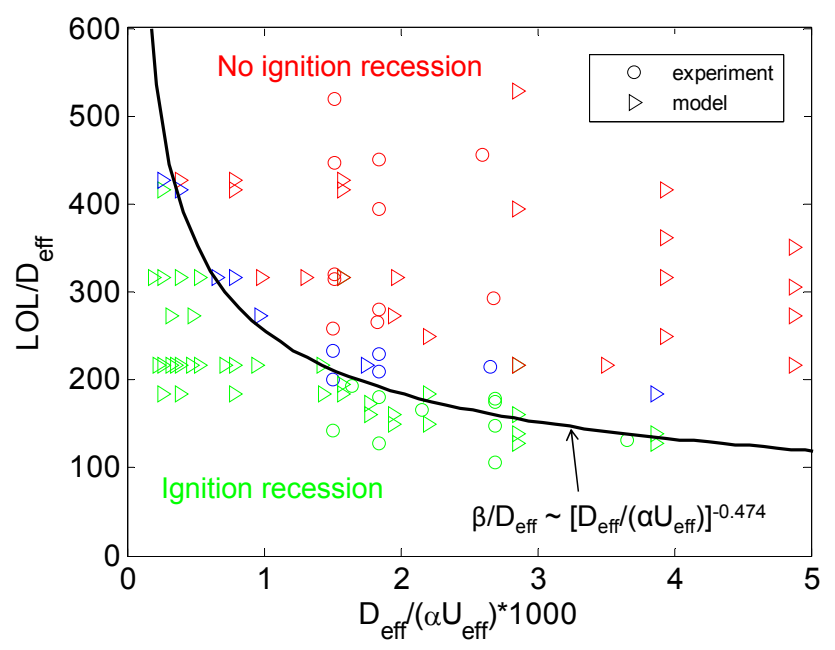




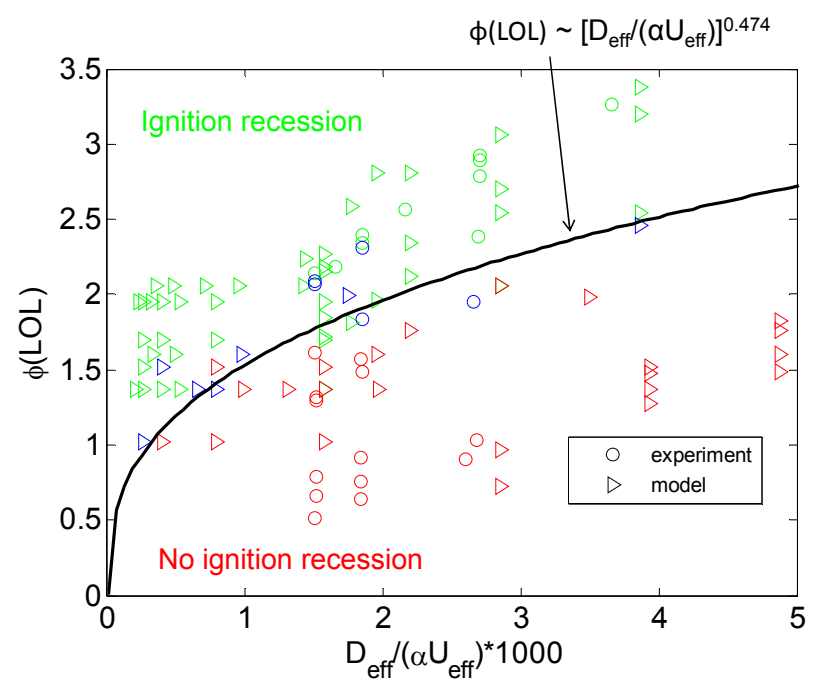

Figure 20 - Predicted boundary for combustion recession using dodecane as the fuel

The lower plot in Figure 20 serves to bring the discussion back around to the original goal of Figure 15, which aimed to define a boundary for combustion recession based on the average equivalence ratio at the flame lift-off length. As shown, the equivalence ratio limit for determining the likelihood of combustion recession depends on the nature of the end-of-injection transient and associated entrainment wave, encapsulated in the dimensionless end-of-injection parameter, $\mathrm{D}_{\mathrm{eff}} /\left(\alpha \mathrm{U}_{\mathrm{eff}}\right)$. Interestingly, the top and bottom portions of Figure 20 are equivalent because LOL/ $\mathrm{D}_{\text {eff }} \sim 1 / \phi(\mathrm{LOL})$. The equivalence of these parameters arises because the equivalence ratio at a given axial distance from the injector, $\phi(x)$, varies as $\sim \mathrm{D}_{\text {eff }} / \mathrm{x}$, and the LOL is merely a given $x$ location [36]. The success of this analysis at defining a boundary for combustion recession is somewhat surprising because $\beta / D_{\text {eff }}$ was based on the simple 1-D transient gas-jet mixingchemistry model without the use of chemistry. However, verification of this boundary was provided by the inclusion of chemistry in the model along with the available range of experimental data outlined in Table 1.

This analysis also suggests that for a given injector orifice diameter and injection pressure or engine operating condition, combustion recession can be controlled via ramp-down duration. Thus, for the control of UHC emissions under low-temperature operating conditions, innovative strategies that can restrict the end-of-injection transient may be successful. Indeed, several methods do exist for accomplishing this objective, namely the use of direct-acting needlelift injectors [37] or pressure-modulated [38] injection systems. Future work is needed to quantify and validate the effect of controlled end-of-injection ramp down on combustion recession likelihood and the resulting impact on UHC.

Finally, while a combination of experimental and 1-D model predictions demonstrate that the non-dimensional scaling variables used to generate Figure 20 are reasonably successful in predicting the likelihood of combustion recession, further experimental data is needed to validate the wider range of combustion recession conditions explored with the model and to address conditions not explored in the current work. In particular, as suggested by limited data in the current work, the likelihood and behavior of combustion recession is likely to be fuel dependent, especially for non-diesel-like fuels with little to no cool-flame behavior. In addition, the current work has focused solely on negative ignition dwell conditions, where a quasi-steady lift-off length is established prior to the end of injection. Combustion recession under positive ignition dwell conditions, where the entrainment wave passes through near-nozzle mixtures long before combustion even begins in the main jet, can be expected to behave quite differently from the conditions studied here. Multiple injections, which further alter the transient near nozzle mixing field are also expected to induce different behaviors in combustion recession.

\section{Summary/Conclusions}

Recent experimental research has shown a correlation between endof-injection over-mixing and unburned hydrocarbon emissions under low-temperature combustion operating conditions. Mixtures near the injector are too fuel-lean to support second-stage ignition reactions. Thus, the lifted flame remains downstream of the flame lift-off location leaving a large region of unburned or partially-reacted fuel upstream. However, under high-temperature combustion operating conditions, there is evidence that the lifted flame propagates back towards the injector after end-of-injection. This process is termed combustion recession.

The goals of this work were threefold. First, identification of combustion recession without interference from soot was achieved through the use of two optical techniques; high-sensitivity schlieren and filtered chemiluminescence. Second, experimental trends of combustion recession with changes in ambient temperature, ambient oxygen concentration, injection pressure, and fuel type were identified. Lastly, a reduced-order model was employed to help interpret the experimental results and provide simplified analyses.

The major conclusions of the experimental results supported by modeling are summarized below.

- As ambient temperature and oxygen concentration are reduced, the likelihood of combustion recession decreases. The combustion recession becomes progressively weaker and the time required for combustion recession increases as these two parameters are decreased.

- During the transition between high and low ambient temperature (or oxygen concentration), the behavior of combustion recession changes from spatially sequential ignition to separated, or isolated, ignition sites that eventually merge.

- As injection pressure is increased, the time required for combustion recession back to the injector increases. Higher injection pressures lead to a faster entrainment wave and thus leaner (but also hotter) mixtures at comparable instances after the end of injection. These lean mixtures have slower kinetics compared to more fuel-rich (but colder) mixtures at lower injection pressures.

- Using a linear ramp down of injection velocity to simulate end of injection, the 1-D model predicts a "saddle point" in the equivalence ratio distribution during ramp down. This saddle point represents the axial location that experiences the greatest relative dilution rate, or most likely to experience over-mixing, and thus unable to support second-stage ignition reactions. The saddle point location could be used to define a boundary for conditions that either will or will not exhibit combustion recession.

- Although no experimental data exists that varies the ramp down duration, the model predicts that a longer ramp down duration 
enhances the likelihood of combustion recession for conditions that would not normally exhibit combustion recession.

\section{References}

1. Musculus, Mark PB, Thierry Lachaux, Lyle M. Pickett, and Cherian A. Idicheria. End-of-injection over-mixing and unburned hydrocarbon emissions in low-temperaturecombustion diesel engines. No. 2007-01-0907. SAE Technical Paper, 2007.

2. Lachaux, Thierry, and Mark PB Musculus. "In-cylinder unburned hydrocarbon visualization during low-temperature compression-ignition engine combustion using formaldehyde PLIF." Proceedings of the Combustion Institute 31, no. 2 (2007): 2921-2929.

3. Scott A. Skeen, Julien Manin, Lyle M. Pickett, Simultaneous formaldehyde PLIF and high-speed schlieren imaging for ignition visualization in high-pressure spray flames, Proceedings of the Combustion Institute, Available online 8 July 2014, ISSN 1540-7489

4. Bobba, Mohan K., Caroline L. Genzale, and Mark PB Musculus. Effect of ignition delay on in-cylinder soot characteristics of a heavy duty diesel engine operating at low temperature conditions. No. 2009-01-0946. SAE Technical Paper, 2009.

5. Singh, Satbir, Rolf D. Reitz, and Mark PB Musculus. 2-color thermometry experiments and high-speed imaging of multimode diesel engine combustion. No. 2005-01-3842. SAE Technical Paper, 2005.

6. Engine Combustion Network. http://www.sandia.gov/ecn/

7. Espey, Christoph, and John E. Dec. Diesel engine combustion studies in a newly designed optical-access engine using highspeed visualization and 2-D laser imaging. No. 930971. SAE Technical Paper, 1993.

8. Pickett, Lyle M., Sanghoon Kook, and Timothy C. Williams. Visualization of diesel spray penetration, cool-flame, ignition, high-temperature combustion, and soot formation using highspeed imaging. No. 2009-01-0658. SAE Technical Paper, 2009.

9. Kook, Sanghoon, Lyle M. Pickett, and Mark PB Musculus. Influence of diesel injection parameters on end-of-injection liquid length recession. No. 2009-01-1356. SAE Technical Paper, 2009.

10. Engine Combustion Network: Constant Volume Diesel Combustion. http://www.sandia.gov/ecn/cvdata/constantVol.php

11. Payri, Raul, Jose M. García-Oliver, Michele Bardi, and Julien Manin. "Fuel temperature influence on diesel sprays in inert and reacting conditions." Applied Thermal Engineering 35 (2012): 185-195.

12. Meijer, Maarten, Bart Somers, Jaclyn Johnson, Jeffrey Naber, Seong-Young Lee, Louis Marie Malbec, Gilles Bruneaux et al. "Engine Combustion Network (ECN): Characterization and comparison of boundary conditions for different combustion vessels." Atomization and Sprays 22, no. 9 (2012).

13. Bardi, Michele, Raul Payri, Louis Marie Malbec, Gilles Bruneaux, Lyle M. Pickett, Julien Manin, Tim Bazyn, and Caroline Genzale. "Engine Combustion Network: comparison of spray development, vaporization, and combustion in different combustion vessels." Atomization and Sprays 22, no. 10 (2012).

14. J.V Pastor, J.M. Garcia-Oliver. R. Novella, W. Vera-Tudela., "Investigation on ignition and combustion characteristics of primary reference fuels under diesel engine conditions" 14 . Tagung "DER ARBEITSPROZESS DES VERBRENNUNGSMOTORS”, Graz, 2013
15. Dec, John E., and Christoph Espey. Chemiluminescence imaging of autoignition in a DI diesel engine. No. 982685. SAE Technical Paper, 1998.

16. Mueller, Charles J., and Glen C. Martin. Effects of oxygenated compounds on combustion and soot evolution in a DI diesel engine: broadband natural luminosity imaging. No. 2002-011631. SAE Technical Paper, 2002.

17. Musculus, Mark PB. Measurements of the influence of soot radiation on in-cylinder temperatures and exhaust NOx in a heavy-duty DI diesel engine. No. 2005-01-0925. SAE Technical Paper, 2005.

18. Pickett, Lyle M., Caroline L. Genzale, Gilles Bruneaux, LouisMarie Malbec, Laurent Hermant, Caspar Ask Christiansen, and Jesper Schramm. "Comparison of diesel spray combustion in different high-temperature, high-pressure facilities." $S A E$ International Journal of Engines 3, no. 2 (2010): 156-181.

19. Engine Combustion Network: Spray A. http://www.sandia.gov/ecn/cvdata/dsearch/frameset.php?nam=1

20. Settles, Gary S. schlieren and shadowgraph techniques. 2001.

21. Pastor, Jose V., Raul Payri, Jose M. Garcia-Oliver, and JeanGuillaume Nerva. Schlieren measurements of the ECN-spray a penetration under inert and reacting conditions. No. 2012-010456. SAE Technical Paper, 2012.

22. Knox, Benjamin W., Genzale, Caroline L. " Reduced-Order Numerical Model for Transient Reacting Diesel Sprays with Detailed Kinetics." International Journal of Engine Research, accepted 2014.

23. Musculus, Mark PB, and Kyle Kattke. Entrainment waves in diesel jets. No. 2009-01-1355. SAE Technical Paper, 2009.

24. Pickett, Lyle M., Julien Manin, Caroline L. Genzale, Dennis L. Siebers, Mark PB Musculus, and Cherian A. Idicheria. Relationship between diesel fuel spray vapor penetration/dispersion and local fuel mixture fraction. No. 201101-0686. SAE Technical Paper, 2011.

25. Wang, Hu, Youngchul Ra, Ming Jia, and Rolf D. Reitz. "Development of a reduced $<\mathrm{i}>\mathrm{n}</ \mathrm{i}>$-dodecane-PAH mechanism and its application for $<\mathrm{i}>\mathrm{n}</ \mathrm{i}>$-dodecane soot predictions." Fuel 136 (2014): 25-36.

26. http://www.sandia.gov/ecn/pub-links/bwk001/ignRecess.php

27. http://www.cmt.upv.es/ECN10.aspx

28. Manin, J., M. Bardi, L. M. Pickett, R. N. Dahms, and J. C. Oefelein. "Microscopic investigation of the atomization and mixing processes of diesel sprays injected into high pressure and temperature environments." Fuel 134 (2014): 531-543.

29. Mastorakos, E., T. A. Baritaud, and T. J. Poinsot. "Numerical simulations of autoignition in turbulent mixing flows." Combustion and Flame 109, no. 1 (1997): 198-223.

30. Lieuwen, Tim, Vince McDonell, Eric Petersen, and Domenic Santavicca. "Fuel flexibility influences on premixed combustor blowout, flashback, autoignition, and stability." Journal of engineering for gas turbines and power 130, no. 1 (2008): 011506.

31. Fritz, Jassin, Martin Kroner, and Thomas Sattelmayer. "Flashback in a swirl burner with cylindrical premixing zone." Journal of engineering for gas turbines and power 126, no. 2 (2004): 276-283.

32. Pickett, Lyle M., Dennis L. Siebers, and Cherian A. Idicheria. Relationship between ignition processes and the liftoff length of diesel fuel jets. No. 2005-01-3843. SAE Technical Paper, 2005.

33. Idicheria, Cherian A., and Lyle M. Pickett. "Effect of EGR on diesel premixed-burn equivalence ratio." Proceedings of the Combustion Institute 31, no. 2 (2007): 2931-2938.

34. Heywood, John B. Internal combustion engine fundamentals. Vol. 930. New York: Mcgraw-hill, 1988. 
35. Musculus, Mark PB, Paul C. Miles, and Lyle M. Pickett. "Conceptual models for partially premixed low-temperature diesel combustion." Progress in Energy and Combustion Science 39, no. 2 (2013): 246-283.

36. Naber, Jeffrey D., and Dennis L. Siebers. Effects of gas density and vaporization on penetration and dispersion of diesel sprays. No. 960034. SAE technical paper, 1996.

37. Schöppe, Ing Detlev, Dipl-Ing Stefan Zülch, Martin Hardy, Dipl-Ing Derk Geurts, Ing Rainer W. Jorach, and Nigel Baker. "Delphi common rail system with direct acting injector." MTZ worldwide 69, no. 10 (2008): 32-38.

38. Kohketsu, Susumu, Keiki Tanabe, and Koji Mori. Flexibly controlled injection rate shape with next generation common rail system for heavy duty DI diesel engines. No. 2000-01-0705. SAE Technical Paper, 2000.

39. Pastor, Jose V., Jean Arregle, and Alberto Palomares. "Diesel spray image segmentation with a likelihood ratio test." Applied Optics 40, no. 17 (2001): 2876-2885.

\section{Acknowledgments}




\section{Definitions/Abbreviations}

$\boldsymbol{\alpha}$

$\boldsymbol{\beta}$

$\phi$

$\tau$

aSORD

$D_{\text {eff }}$

ECN

LOL

$m_{\text {ent }}$
Ramp down duration

Saddle point location

Equivalence ratio

Ignition delay

After start-of-ramp-down

Effective diameter

Engine Combustion Network

Flame lift-off length

Ambient entrainment rate
$\mathbf{U}_{\text {eff }}$

UHC

$\mathbf{x}$
Effective velocity

Unburned hydrocarbons

Axial distance from injector 